\title{
MULTIDRUG RESISTANT BACTERIAL PATHOGENS IN EGGS COLLECTED FROM BACKYARD CHICKENS
}

\author{
SAMAH EID ${ }^{*}$; SOAD A. NASEF ${ }^{* *}$ and AHMED M. ERFAN ${ }^{* * *}$ \\ *Bacteriology Dept., ${ }^{* *}$ Poultry Diseases Dept., ${ }^{* * *}$ Biotechnology Dept. \\ Reference Laboratory for Veterinary Quality Control on Poultry Production, Animal Health Research Institute, Nadi El-Seid \\ St., P.O. Box 246, Dokki, Giza 12618, Egypt. \\ Email: samaheid@ymail.com
}

\section{ABSTRACT}

Received at: $28 / 10 / 2014$

Accepted: 5/1/2015
A total of two hundred eggs collected from backyard balady chickens were examined for the presence of Salmonella spp., E. coli, and Coagulase Positive Staphylococci. Out of the total examined samples, no Salmonella was detected. A total of 36 E. coli strains were isolated with an overall isolation rate of $18 \%$. Eighty (40\%) Coagulase Positive Staphylococci isolates were detected. Serotyping of E.coli isolates revealed the predominance of O 27 at a rate of $22 \%$ among the 13 identified serotypes. However, 5 (14\%) of the E. coli isolates were untypeable. The antibiotic susceptibility pattern of Coagulase Positive Staphylococci was studied against 15 different chemotherapeutic agents. The highest resistance rates were detected against oxytetracyclin, oxacillin and trimethoprim sulphamethazole with resistance rates of $90 \%, 86.7 \%$ and $86.7 \%$, respectively. The highest sensitivity rate was detected towards ampicillin with a percentage of $87 \%$. E. coli isolates were tested for its susceptibility against 14 different antibiotics, the highest resistance rates were recorded against trimethoprim -sulphamethazole, doxycycline, tetracycline and amoxycillin with resistance rates $94.1 \%, 93.2 \%, 92.9 \%$, and $92.3 \%$, respectively. While the highest sensitivity rates were detected for colistin, cefotaxim, gentamycin and ciprofloxacin with sensitivity rates of 94.4\%, 76.5\% 59.8\% and 55.6\%, respectively. The antibiotic susceptibility results were judged by PCR, for E. coli strains, the bla $a_{T E M}$, sul1 and $\operatorname{tet} \mathrm{A}(\mathrm{A})$ genes were tested for the B-lactams, trimethoprim sulphamethazone and tetracyclines, respectively. While the mecA, bla $\mathrm{Z}$ and tet $\mathrm{K}$ genes were tested for the evaluation of the susceptibility of Coagulase Positive Staphylococci against oxacillin, B-lactams, and tetracyclines, respectively. E. coli virulence was tested by PCR through the testing of iss, eaeA, stx 1 , stx 2 , tsh and papC genes. While the virulence of Coagulase Positive Staphylococci was estimated through testing of the enterotoxins genes in addition to coagulase, spa and $h l g$ genes.

Key words: MDR bacteria, E.coli, PCR, balady chicken eggs.

\section{INTRODUCTION}

Table eggs are consumed worldwide and are considered the most nutritious inexpensive source of protein that can be part of a healthy diet. However poultry may carry bacteria that can cause illness, infected birds do not usually appear sick and even unbroken clean fresh shell eggs may contain harmful bacteria. (Barbara and RON, 2010).

There is now considerable evidence that transfer of antimicrobial resistance from food-producing animals to humans directly via the food chain is a likely route of spread, transmission by direct handling or close contact between infected animals and humans, transmission via contaminated animal products, particularly but not exclusively food products. The World Organisation for Animal
Health (OIE) has developed a list of antibiotics categorized by the need for their use in animal treatment; The category 'veterinary critically important antimicrobials' includes fluoroquinolones, cephalosporins and macrolides, as well as a number of other families of antibiotics. Thus these antibiotics may all affect bacteria in both animal and human treatment settings (Wooldridge, 2012).

Escherichia coli is one of the common microbial flora of gastrointestinal tract of poultry and human, resistant E. coli strains from the gut often cause contamination of eggs during lay with multi resistant E. coli (Turtura et al., 1990).

Egg-associated Salmonellosis is a public health problem, the use of antibiotics in animals disrupts normal flora of intestine, resulting in emergence of antibiotic-resistant Salmonellae and their prolonged 
fecal shedding into the environment (Ahmed et al., 2011).

Staphylococcus is considered to be a normal flora of chickens, isolated from the skin and feathers as well as in the respiratory and intestinal tracts (Casey et al., 2007). However, some of the common forms of Staphylococci are associated with poultry infections. Increasing attention has been given to the role of poultry and poultry products, including eggs, as a potential source of infections in humans induced by antibiotic-resistant Staphylococcus strains (Abulreesh and Organji 2011).

Backyards flocks are reared under limited or no veterinary supervision. In such production systems, antimicrobials are freely used as feed or water additives (Otalu et al., 2011). These practices can facilitate the emergence and spread of antibiotic resistant pathogens among birds with possible transmission to humans. Backyard chickens are extensively reared in close proximity to human dwellings and therefore play an important role in environmental contamination, in addition to serving as significant vehicles for the transfer of pathogens to humans by way of handling of live birds or consumption of contaminated meat and other poultry products. (Suleiman et al., 2013).

Thus the present study aimed to investigate the prevalence of multidrug resistant bacteria in egg produced from backyard chicken.

\section{MATERIAL and METHODS}

\section{SAMPLING:}

A total of two hundred eggs were collected from house hold backyard balady chicken from several villages in Sharkia governorate during summer 2014. Each egg was uniquely identified, and transported in a sterile plastic bag to the reference laboratory for veterinary quality control on poultry production, Sharkia branch, kept in refrigerator at $2-5{ }^{\circ} \mathrm{C}$ till examined.

\section{Sample preparation:}

From each egg, the contents were separated from the shell; Each of the contents and the shell was collected in a separate sterile flask. Non selective pre-enrichment was performed by adding BPW in 1:10 dilution rate, samples were well mixed and incubated at $37^{\circ} \mathrm{C} \pm 1$ for 18 hours \pm 2 .

\section{Isolation and Identification:}

Samples were examined for the detection of Salmonella Spp., Coagulase Positive Staphylococci and E.coli according to ISO 6579:2002-COR 2004, ISO 6888-1:1999-AM:2003 and (Kreig et al., 1984), respectively.

Serotyping: E. coli isolates were serotyped in Reference Laboratory for Veterinary Quality Control on Poultry Production using commercially available kits (Test Sera Enteroclon, Anti -Coli, SIFIN Berlin, Germany).

Antibiogram: Antibiotic sensitivity was performed using Mueller Hinton Agar plates (HIMEDIA) using antibiotic discs of 14 commonly used chemotherapeutic agents, for E.coli isolates, and 15 commonly used chemotherapeutic agents for Coagulase Positive Staphylococci isolates according to (Bauer et al., 1966). Interpretation of the results based on the diameter of the inhibition zones produced was done according to (CLSI, 2011).

\section{DNA extraction:}

DNA extraction from samples was performed using the QIAamp DNA Mini kit (Qiagen, Germany, $\mathrm{GmbH}$ ) with few modifications from the manufacturer's recommendations. Briefly, $200 \mu \mathrm{l}$ of the sample was added to $20 \mu \mathrm{l}$ of proteinase $\mathrm{K}$ and $200 \mu \mathrm{l}$ of $\mathrm{AL}$ lysis buffer and incubated at $56^{\circ} \mathrm{C}$ for $10 \mathrm{~min}$ in a Biometra Tsc thermal block. After incubation, $200 \mu 1$ of $100 \%$ ethanol was added to the lysate and vortexed. The sample was then washed twice and centrifuged according to the manufacturer's instructions. DNA was eluted with $100 \mu \mathrm{l}$ of elution buffer supplied in the kit.

\section{Oligonucleotide Primers:}

Different primers used in PCR were supplied from Metabion (Germany) and Biobasic (Canada) and are listed in Table (1) and Table (2).

\section{PCR amplification:}

A $25-\mu 1$ master mix reaction containing $12.5 \mu 1$ of Emerald Amp Max PCR Master Mix (Takara, Japan), $1 \mu \mathrm{l}$ of 20 pmol conc. of each primer, $4.5 \mu 1$ of water, and $6 \mu \mathrm{l}$ of template DNA. The reactions were performed in Applied biosystem 2720 thermal cyclers.

\section{Analysis of the PCR Products:}

Fifteen microliters of each PCR product were loaded in each gel lane of $1.5 \%$ agarose gel (Applichem). Electrophoresis was done in $1 \mathrm{x}$ TBE buffer using 5V/cm gradients. A 100 bp DNA Ladder (Fermentas) was used to determine the fragment sizes. The PCR photos were photographed and analyzed by using a gel documentation system (Alpha Innotech, Biometra, Germany) through its computer software.

\section{RESULTS}

\section{Prevalence of bacterial isolates:}

Out of the total examined 200 eggs, no Salmonella was detected neither from on the shell nor from the contents. Regarding E.coli a total of 36 isolates were detected with an overall isolation rate of $18 \%$. Out of total E.coli isolates, 21(10.5\%) isolates were isolated from on the shell, a total of $9(4.5 \%)$ from the contents, and $6(3 \%)$ from both shell and contents, respectively. Concerning the isolation rates of Coagulase Positive Staphylococci, a total of 80 (40\%) isolates were detected; Of which, 29 (14.5\%) 
isolates were detected from the shell,15 (7.5\%) isolates from contents, and $36(18 \%)$ isolates from both shell and contents. Out of total examined 200 eggs, $15(7.5 \%)$ harbor both Coagulase Positive Staphylococci and E.coli., as shown in "Fig.1",and "Table 3".

In the present study 36 E.coli were isolated out of total 200 examined eggs with an overall prevalence rate of $18 \%$. Serotyping of the isolates by slide agglutination technique revealed the distribution of the detected isolates in 13 different serotypes, which belonged to 6 somatic "O" groups "2,3,4,5,6 ,and 8" . Five isolates belonged to Poly 2 were detected, of which 1 strain 091 isolated from on the shell, O 125 (3 isolates were detected, of which 2 isolates from on the shell, and 1 isolate from contents), respectively; And O 166 ( 1 isolate) from on the shell. Poly 3 ; O 145 (1 isolate) from on the shell. Poly 4 (14 isolates), of which 3 strains were O6 $(2,1)$ from on the shell and contents, respectively; Eight isolates were identified as $\mathrm{O} 27(2,2,4)$ from on the shell, contents, and from both on the shell and contents, respectively; Also 3 strains O $159(2,1)$ from on the shell and contents, respectively. Poly 5 (2 isolates) 1 strain $\mathrm{O} 25,1$ strain $\mathrm{O} 153$ both were isolated from on the shell. In addition to 4 strains identified as Poly 6 of which 1 strain O 115 from on the shell, 3 strains O $169(2,1)$ from the contents and from both on the shell and contents, respectively. Finally 5 isolates were identified as Poly 8 of which 4 strains belonged to $\mathrm{O} 152(2,1,1)$ from on the shell, contents and from both on the shell and contents, respectively; One strain O 29 from on the shell. Five untypeable isolates were detected $(4,1)$ from on the shell and contents, respectively as shown in Table 3".

Antibiotic susceptibility pattern of E.coli isolates was studied using agar disc diffusion technique against 14 commonly field used chemotherapeutic agents. The study detected the prevalence of multidrug resistant MDR E.coli; As 34 (94.1\%) of isolates were resistant to more than 5 chemotherapeutic agents, $11(29.4 \%)$ of the isolates were resistant to more than 9 chemotherapeutic agents. The highest resistance rates were recorded against trimethoprim sulphate, doxycyclin, tetracycline, and amoxicillin; 94.1\%, 93.2\%, 92.9\%, and $92.3 \%$, respectively. While the highest sensitivity rates were detected to colistin, cefotaxim, gentamycin, and ciprofloxacin; 94.4.\%, 76.5\%, $59.8 \%$, and 55.6, respectively as shown in "Table 4", and "Fig.2".

Antibiotic susceptibility pattern of Coagulase Positive Staphylococci isolates was studied using agar disc diffusion technique against 15 commonly field used chemotherapeutic agents. The study detected the prevalence of multidrug resistant Coagulase Positive Staphylococci; As 72 (90\%) of isolates were resistant to 3 and more chemotherapeutic agents, $29(36.7 \%)$ of isolates were resistant against 9 and more chemotherapeutic agents. The most predominant resistance rates were recorded against oxytetracyclin (90\%), followed by trimethoprim-sulphamethazone, and oxacillin $86.7 \%$, each. The least resistance rates were recorded against ampicillin, ciprofloxacin, and gentamycin; $13.1 \%$, $26.7 \%$, and $30 \%$, respectively, as shown in "Table 5 " and "Fig 3".

(Table 6) showing the relation between the PCR results of the different antibiotic resistance genes and antibiotic resistance profile of Coagulase Positive Staphylococci.

(Table 7) showing the PCR results of the different virulence genes of coagulase positive staphylococci; Positive results were detected for all genes except for Sea and Sed genes.

(Table 8) showing the relation between the PCR results of the different antibiotic resistance genes and antibiotic resistance profile of E. coli.

(Table 9) showing the PCR results of the different virulence genes of E. coli. All the genes were positively amplified in some isolates except for stx 1 gene.

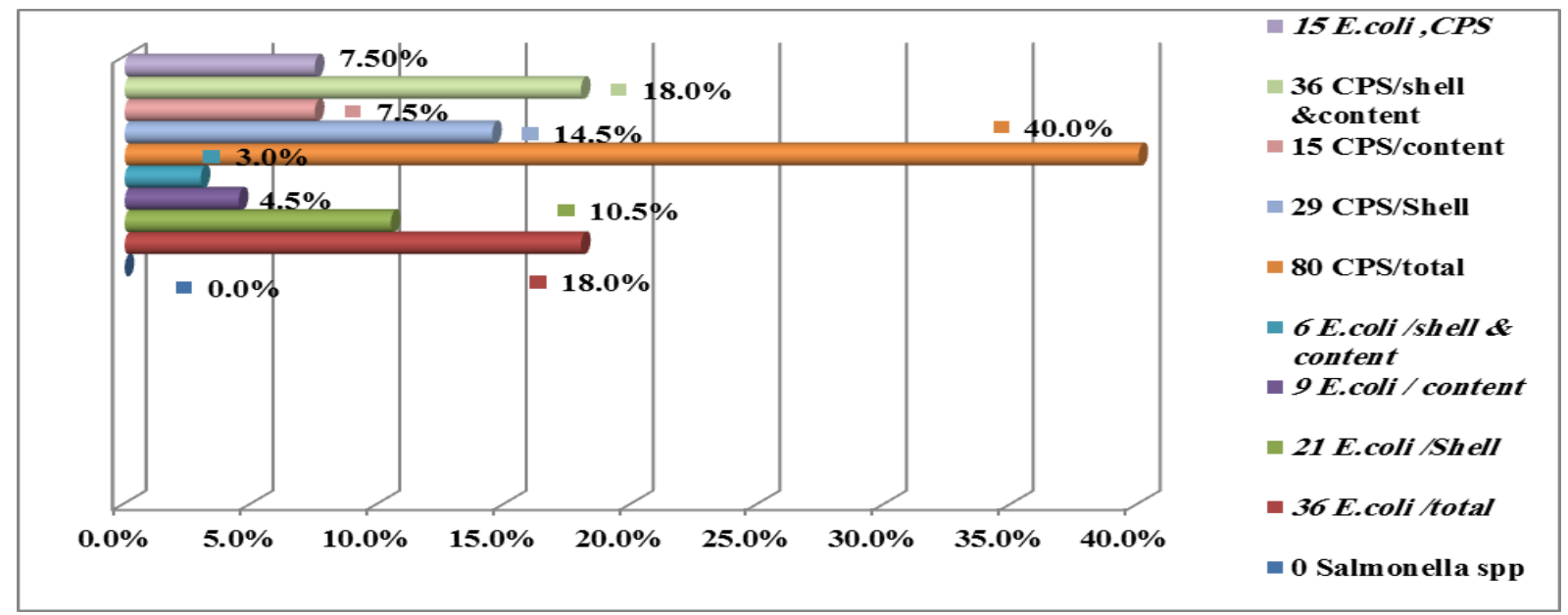

Figure 1: Prevalence rates of isolates. 


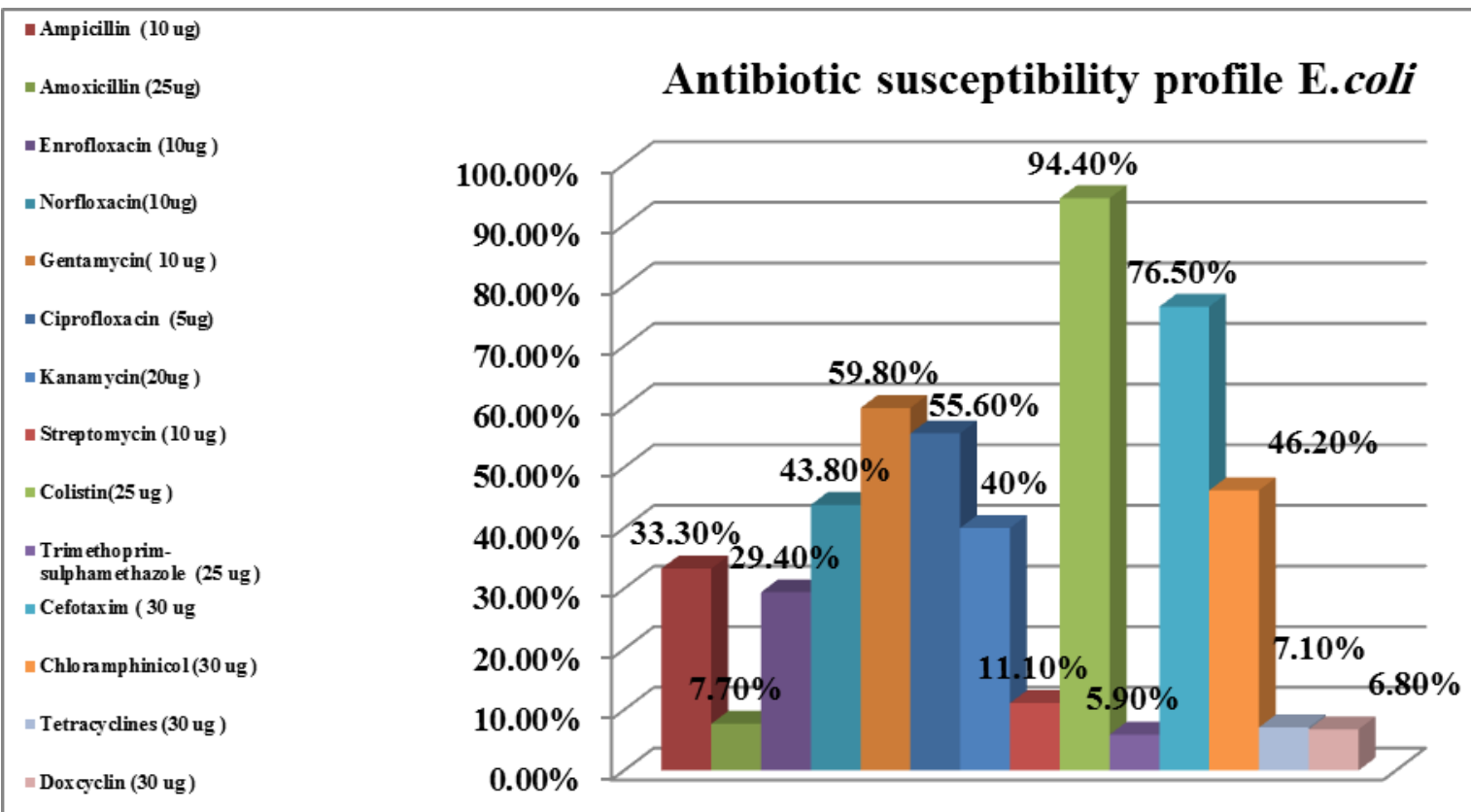

Figure 2: Antibiotic susceptibility profile of E.coli isolates.

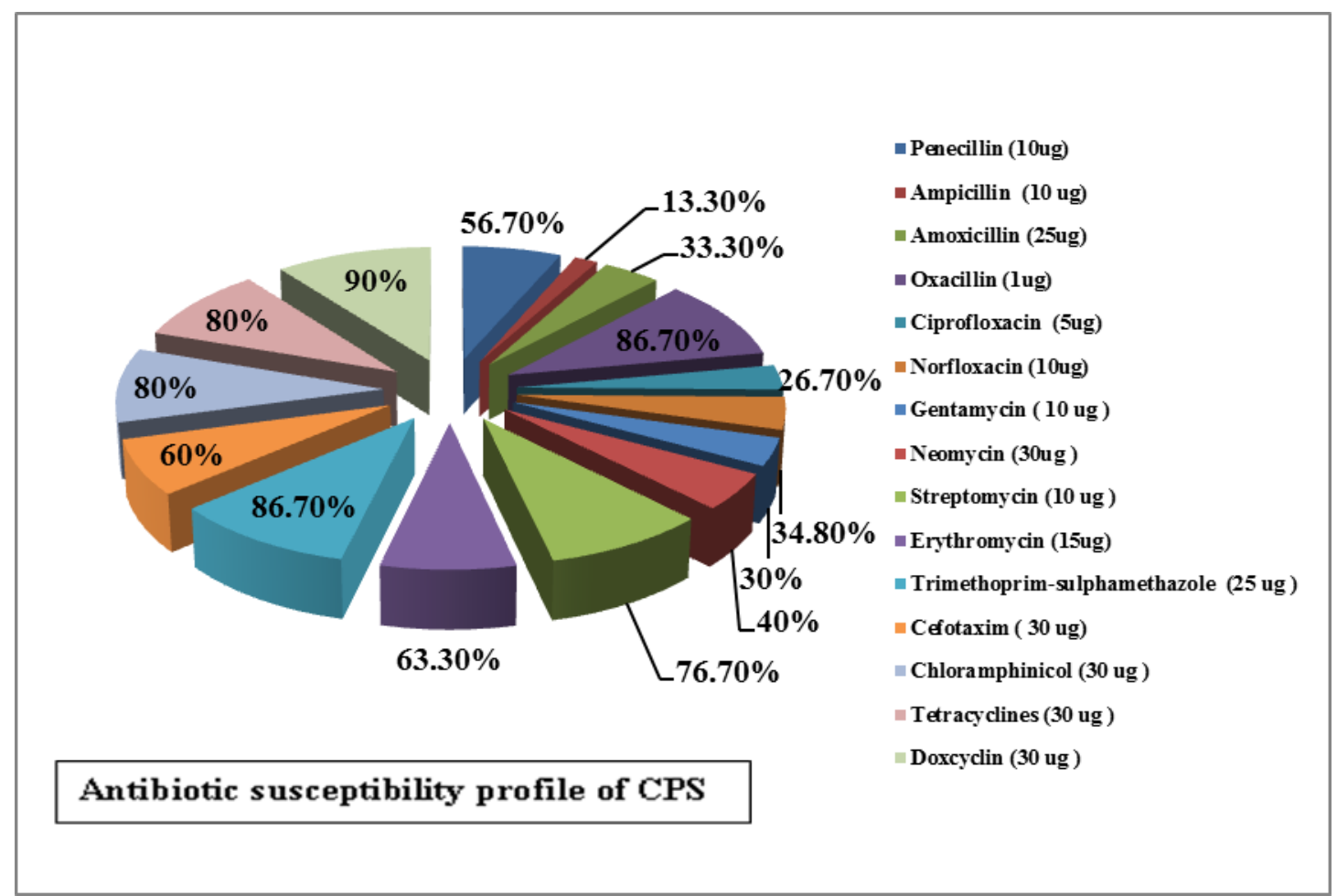

Figure 3:Antibiotic susceptibility pattern of Coagulase Positive Staphylococci isolates. 
Table 1: Sequences and cycling conditions of the different PCR primers used for amplification of different virulence genes of E. coli and CPS.

\begin{tabular}{|c|c|c|c|c|c|c|c|c|c|}
\hline \multirow[t]{2}{*}{ Gene } & \multirow{2}{*}{$\begin{array}{c}\text { Disease } \\
\text { agent }\end{array}$} & \multirow[t]{2}{*}{ Primers sequences } & \multirow{2}{*}{$\begin{array}{c}\text { Amplified } \\
\text { segment }\end{array}$} & \multirow{2}{*}{$\begin{array}{c}\text { Primary } \\
\text { denaturation }\end{array}$} & \multicolumn{3}{|c|}{ Amplification (35 cycles) } & \multirow{2}{*}{$\begin{array}{c}\text { Final } \\
\text { extension }\end{array}$} & \multirow[t]{2}{*}{ Reference } \\
\hline & & & & & $\begin{array}{c}\text { Secondary } \\
\text { denaturation }\end{array}$ & Annealing & $\overline{\text { Extension }}$ & & \\
\hline eaeA & E. coli & $\begin{array}{c}\text { GACCCGGCACAA } \\
\text { GCATAAGC } \\
\text { CCACCTGCAGCA } \\
\text { ACAAGAGG }\end{array}$ & $384 \mathrm{bp}$ & $\begin{array}{c}94^{\circ} \mathrm{C} \\
5 \mathrm{~min} .\end{array}$ & $\begin{array}{c}94^{\circ} \mathrm{C} \\
45 \mathrm{sec} .\end{array}$ & $\begin{array}{c}54^{\circ} \mathrm{C} \\
45 \mathrm{sec}\end{array}$ & $\begin{array}{c}72^{\circ} \mathrm{C} \\
45 \mathrm{sec}\end{array}$ & $\begin{array}{l}72^{\circ} \mathrm{C} \\
7 \mathrm{~min} .\end{array}$ & $\begin{array}{c}\text { (Wen-jie } \\
\text { et al., 2008) }\end{array}$ \\
\hline papC & & $\begin{array}{c}\text { TGATATCACGCA } \\
\text { GTCAGTAGC } \\
\text { CCGGCCATATTCA } \\
\text { CACATAA }\end{array}$ & $501 b p$ & $\begin{array}{c}94^{\circ} \mathrm{C} \\
10 \mathrm{~min} .\end{array}$ & $\begin{array}{c}94^{\circ} \mathrm{C} \\
45 \mathrm{sec} .\end{array}$ & $\begin{array}{c}59^{\circ} \mathrm{C} \\
45 \mathrm{sec}\end{array}$ & $\begin{array}{c}72^{\circ} \mathrm{C} \\
45 \mathrm{sec}\end{array}$ & $\begin{array}{c}72^{\circ} \mathrm{C} \\
10 \mathrm{~min} .\end{array}$ & \\
\hline iss & & $\begin{array}{c}\text { ATGTTATTTTCTG } \\
\text { CCGCTCTG } \\
\text { CTATTGTGAGCA } \\
\text { ATATACCC }\end{array}$ & $266 \mathrm{bp}$ & $\begin{array}{l}94^{\circ} \mathrm{C} \\
5 \mathrm{~min} .\end{array}$ & $\begin{array}{c}94^{\circ} \mathrm{C} \\
30 \mathrm{sec} .\end{array}$ & $\begin{array}{c}54^{\circ} \mathrm{C} \\
30 \mathrm{sec} .\end{array}$ & $\begin{array}{c}72^{\circ} \mathrm{C} \\
30 \mathrm{sec} .\end{array}$ & $\begin{array}{l}72^{\circ} \mathrm{C} \\
7 \mathrm{~min} .\end{array}$ & $\begin{array}{c}\text { (Yaguchi } \\
\text { et al., 2007) }\end{array}$ \\
\hline$S t x 1$ & & $\begin{array}{c}\text { ACACTGGATGAT } \\
\text { CTCAGTGG } \\
\text { CTGAATCCCCCTC } \\
\text { CATTATG } \\
\end{array}$ & $614 b p$ & $\begin{array}{c}94^{\circ} \mathrm{C} \\
10 \mathrm{~min} .\end{array}$ & $\begin{array}{c}94^{\circ} \mathrm{C} \\
1 \mathrm{~min} .\end{array}$ & $\begin{array}{c}58^{\circ} \mathrm{C} \\
1 \mathrm{~min} .\end{array}$ & $\begin{array}{l}72^{\circ} \mathrm{C} \\
1 \mathrm{~min} .\end{array}$ & $\begin{array}{c}72^{\circ} \mathrm{C} \\
10 \mathrm{~min} .\end{array}$ & $\begin{array}{c}\text { (Dipineto } \\
\text { et al., 2006) }\end{array}$ \\
\hline Stx 2 & & $\begin{array}{c}\text { CCATGACAACGG } \\
\text { ACAGCAGTT } \\
\text { CCTGTCAACTGAGC } \\
\text { AGCACTTTG }\end{array}$ & $779 \mathrm{bp}$ & $\begin{array}{c}94^{\circ} \mathrm{C} \\
10 \mathrm{~min} .\end{array}$ & $\begin{array}{c}94^{\circ} \mathrm{C} \\
1 \mathrm{~min} .\end{array}$ & $\begin{array}{c}58^{\circ} \mathrm{C} \\
1 \mathrm{~min} .\end{array}$ & $\begin{array}{l}72^{\circ} \mathrm{C} \\
1 \mathrm{~min} .\end{array}$ & $\begin{array}{c}72^{\circ} \mathrm{C} \\
10 \mathrm{~min} .\end{array}$ & \\
\hline tsh & & $\begin{array}{c}\text { GGTGGTGCACTG } \\
\text { GAGTGG } \\
\text { AGTCCAGCG } \\
\text { TGATAG TGG }\end{array}$ & $620 \mathrm{bp}$ & $\begin{array}{c}94^{\circ} \mathrm{C} \\
10 \mathrm{~min} .\end{array}$ & $\begin{array}{c}94^{\circ} \mathrm{C} \\
45 \mathrm{sec} .\end{array}$ & $\begin{array}{c}54^{\circ} \mathrm{C} \\
45 \mathrm{sec} .\end{array}$ & $\begin{array}{c}72^{\circ} \mathrm{C} \\
45 \mathrm{sec} .\end{array}$ & $\begin{array}{c}72^{\circ} \mathrm{C} \\
10 \mathrm{~min} .\end{array}$ & $\begin{array}{c}\text { (Delicato } \\
\text { et al., 2003) }\end{array}$ \\
\hline hlg & $\begin{array}{c}\text { Coagulase } \\
\text { positive } \\
\text { Staphylococci }\end{array}$ & $\begin{array}{c}\text { GCCAATCCGTTATT } \\
\text { AGAAAATGC } \\
\text { CCATAGACGTAG } \\
\text { CAACGGAT } \\
\end{array}$ & $937 \mathrm{bp}$ & $\begin{array}{c}94^{\circ} \mathrm{C} \\
15 \mathrm{~min} .\end{array}$ & $\begin{array}{c}94^{\circ} \mathrm{C} \\
1.5 \mathrm{~min} .\end{array}$ & $\begin{array}{c}55^{\circ} \mathrm{C} \\
1.5 \mathrm{~min} .\end{array}$ & $\begin{array}{l}72^{\circ} \mathrm{C} \\
1.5 \\
\min .\end{array}$ & $\begin{array}{c}72^{\circ} \mathrm{C} \\
10 \mathrm{~min} .\end{array}$ & $\begin{array}{c}\text { (Kumar } \\
\text { et al., 2009) }\end{array}$ \\
\hline$\overline{C o a}$ & & $\begin{array}{c}\text { ATAGAGATGCTG } \\
\text { GTACAGG } \\
\text { GCTTCCGATTGTT } \\
\text { CGATGC }\end{array}$ & $\begin{array}{c}\text { Four } \\
\text { different } \\
\text { types of } \\
\text { bands may } \\
\text { be } \\
\text { detected } \\
350 \mathrm{bp} \text { or } \\
430 \mathrm{bp} \text { or } \\
570 \mathrm{bp} \text { or } \\
630 \mathrm{bp} \\
\end{array}$ & $\begin{array}{c}94^{\circ} \mathrm{C} \\
10 \mathrm{~min} .\end{array}$ & $\begin{array}{c}94^{\circ} \mathrm{C} \\
45 \mathrm{sec} .\end{array}$ & $\begin{array}{c}55^{\circ} \mathrm{C} \\
45 \mathrm{sec} .\end{array}$ & $\begin{array}{c}72^{\circ} \mathrm{C} \\
45 \mathrm{sec} .\end{array}$ & $\begin{array}{c}72^{\circ} \mathrm{C} \\
10 \mathrm{~min} .\end{array}$ & $\begin{array}{l}\text { (Iyer and } \\
\text { Kumosani, } \\
\text { 2011) }\end{array}$ \\
\hline spa & & $\begin{array}{c}\text { TCAACAAAGAACAA } \\
\text { CAAAATGC } \\
\text { GCTTTCGGTGCTT } \\
\text { GAGATTC }\end{array}$ & $226 \mathrm{bp}$ & $\begin{array}{c}94^{\circ} \mathrm{C} \\
5 \mathrm{~min} .\end{array}$ & $\begin{array}{c}94^{\circ} \mathrm{C} \\
30 \mathrm{sec} .\end{array}$ & $\begin{array}{c}55^{\circ} \mathrm{C} \\
30 \mathrm{sec} .\end{array}$ & $\begin{array}{c}72^{\circ} \mathrm{C} \\
30 \mathrm{sec} .\end{array}$ & $\begin{array}{l}72^{\circ} \mathrm{C} \\
7 \mathrm{~min} .\end{array}$ & $\begin{array}{c}\text { (Wada } \\
\text { et al., 2010) }\end{array}$ \\
\hline Sea & & $\begin{array}{c}\text { GGTTATCAATGTG } \\
\text { CGGGTGG } \\
\text { CGGCACTTTTTTC } \\
\text { TCTTCGG }\end{array}$ & 102 bp & $\begin{array}{c}94^{\circ} \mathrm{C} \\
5 \mathrm{~min} .\end{array}$ & $\begin{array}{c}94^{\circ} \mathrm{C} \\
30 \mathrm{sec} .\end{array}$ & $\begin{array}{c}50^{\circ} \mathrm{C} \\
30 \mathrm{sec} .\end{array}$ & $\begin{array}{c}72^{\circ} \mathrm{C} \\
30 \mathrm{sec} .\end{array}$ & $\begin{array}{l}72^{\circ} \mathrm{C} \\
7 \mathrm{~min} .\end{array}$ & $\begin{array}{r}\text { (Mehrotra } \\
\text { et al., 2000) }\end{array}$ \\
\hline $\mathrm{Seb}$ & & $\begin{array}{c}\text { GTATGGTGGTGT } \\
\text { AACTGAGC } \\
\text { CCAAATAGTGAC } \\
\text { GAGTTAGG }\end{array}$ & $164 \mathrm{bp}$ & $\begin{array}{l}94^{\circ} \mathrm{C} \\
5 \mathrm{~min} .\end{array}$ & $\begin{array}{c}94^{\circ} \mathrm{C} \\
30 \mathrm{sec} .\end{array}$ & $\begin{array}{c}50^{\circ} \mathrm{C} \\
30 \mathrm{sec} .\end{array}$ & $\begin{array}{c}72^{\circ} \mathrm{C} \\
30 \mathrm{sec} .\end{array}$ & $\begin{array}{l}72^{\circ} \mathrm{C} \\
7 \mathrm{~min} .\end{array}$ & \\
\hline Sec & & $\begin{array}{c}\text { AGATGAAGTAGT } \\
\text { TGATGTGTATGG } \\
\text { CACACTTTTAGAA } \\
\text { TCAACCG } \\
\end{array}$ & $451 \mathrm{bp}$ & $\begin{array}{c}94^{\circ} \mathrm{C} \\
10 \mathrm{~min} .\end{array}$ & $\begin{array}{c}94^{\circ} \mathrm{C} \\
45 \mathrm{sec} .\end{array}$ & $\begin{array}{c}50^{\circ} \mathrm{C} \\
45 \mathrm{sec} .\end{array}$ & $\begin{array}{c}72^{\circ} \mathrm{C} \\
45 \mathrm{sec} .\end{array}$ & $\begin{array}{c}72^{\circ} \mathrm{C} \\
10 \mathrm{~min} .\end{array}$ & \\
\hline Sed & & $\begin{array}{c}\text { CCAATAATAGGA } \\
\text { GAAAATAAAAG } \\
\text { ATTGGTATTTTTT } \\
\text { TTCGTTC }\end{array}$ & $278 \mathrm{bp}$ & $\begin{array}{c}94^{\circ} \mathrm{C} \\
5 \mathrm{~min} .\end{array}$ & $\begin{array}{c}94^{\circ} \mathrm{C} \\
30 \mathrm{sec} .\end{array}$ & $\begin{array}{c}48^{\circ} \mathrm{C} \\
30 \mathrm{sec} .\end{array}$ & $\begin{array}{c}72^{\circ} \mathrm{C} \\
30 \mathrm{sec} .\end{array}$ & $\begin{array}{c}72^{\circ} \mathrm{C} \\
7 \mathrm{~min} .\end{array}$ & \\
\hline See & & $\begin{array}{c}\text { AGGTTTTTTCACA } \\
\text { GGTCATCC } \\
\text { CTTTTTTTTCTTC } \\
\text { GGTCAATC }\end{array}$ & $209 \mathrm{bp}$ & $\begin{array}{c}94^{\circ} \mathrm{C} \\
5 \mathrm{~min} .\end{array}$ & $\begin{array}{c}94^{\circ} \mathrm{C} \\
30 \mathrm{sec} .\end{array}$ & $\begin{array}{c}50^{\circ} \mathrm{C} \\
30 \mathrm{sec} .\end{array}$ & $\begin{array}{c}72^{\circ} \mathrm{C} \\
30 \mathrm{sec} .\end{array}$ & $\begin{array}{c}72^{\circ} \mathrm{C} \\
7 \mathrm{~min} .\end{array}$ & \\
\hline
\end{tabular}


Assiut Vet. Med. J. Vol. 61 No 144 January 2015

Table 2: Sequences and cycling conditions of the different PCR primers used for amplification of different antibiotic resistance genes of $E$. coli, and CPS.

\begin{tabular}{|c|c|c|c|c|c|c|c|c|c|}
\hline \multirow[t]{2}{*}{ Gene } & \multirow{2}{*}{$\begin{array}{c}\text { Disease } \\
\text { agent }\end{array}$} & \multirow[t]{2}{*}{ Primers sequences } & \multirow{2}{*}{$\begin{array}{c}\text { Amplified } \\
\text { segment }\end{array}$} & \multirow{2}{*}{$\begin{array}{c}\text { Primary } \\
\text { denaturation }\end{array}$} & \multicolumn{3}{|c|}{ Amplification (35 cycles) } & \multirow{2}{*}{$\begin{array}{c}\text { Final } \\
\text { extension }\end{array}$} & \multirow[t]{2}{*}{ Reference } \\
\hline & & & & & $\begin{array}{c}\text { Secondary } \\
\text { denaturation }\end{array}$ & Annealing & Extension & & \\
\hline${ }^{b l a}$ TEM & \multirow[t]{3}{*}{ E. coli } & $\begin{array}{c}\text { ATCAGCAATAAA } \\
\text { CCAGC } \\
\text { CCCCGAAGAACG } \\
\text { TTTTC } \\
\end{array}$ & $516 \mathrm{bp}$ & $\begin{array}{c}94^{\circ} \mathrm{C} \\
10 \mathrm{~min} .\end{array}$ & $\begin{array}{c}94^{\circ} \mathrm{C} \\
45 \mathrm{sec} .\end{array}$ & $\begin{array}{c}54^{\circ} \mathrm{C} \\
45 \mathrm{sec} .\end{array}$ & $\begin{array}{c}72^{\circ} \mathrm{C} \\
45 \mathrm{sec} .\end{array}$ & $\begin{array}{c}72^{\circ} \mathrm{C} \\
10 \mathrm{~min} .\end{array}$ & $\begin{array}{c}\text { Colom } \\
\text { et al., } 2003\end{array}$ \\
\hline Sul1 & & $\begin{array}{c}\text { CGG CGT GGG } \\
\text { CTA CCT GAA CG } \\
\text { GCC GAT CGC } \\
\text { GTG AAG TTC CG }\end{array}$ & $433 \mathrm{bp}$ & $\begin{array}{c}94^{\circ} \mathrm{C} \\
10 \mathrm{~min} .\end{array}$ & $\begin{array}{c}94^{\circ} \mathrm{C} \\
45 \mathrm{sec} .\end{array}$ & $\begin{array}{c}60^{\circ} \mathrm{C} \\
45 \mathrm{sec} .\end{array}$ & $\begin{array}{c}72^{\circ} \mathrm{C} \\
45 \mathrm{sec} .\end{array}$ & $\begin{array}{c}72^{\circ} \mathrm{C} \\
10 \mathrm{~min} .\end{array}$ & $\begin{array}{c}\text { (Ibekwe } e t \\
a l ., 2011)\end{array}$ \\
\hline $\operatorname{Tet} \mathbf{A}(\mathbf{A})$ & & $\begin{array}{c}\text { GGTTCACTCGAAC } \\
\text { GACGTCA } \\
\text { CTGTCCGACAAGT } \\
\text { TGCATGA }\end{array}$ & 576 bp & $\begin{array}{c}94^{\circ} \mathrm{C} \\
10 \mathrm{~min} .\end{array}$ & $\begin{array}{c}94^{\circ} \mathrm{C} \\
45 \mathrm{sec} .\end{array}$ & $\begin{array}{c}50^{\circ} \mathrm{C} \\
45 \mathrm{sec} .\end{array}$ & $\begin{array}{c}72^{\circ} \mathrm{C} \\
45 \mathrm{sec} .\end{array}$ & $\begin{array}{c}72^{\circ} \mathrm{C} \\
10 \mathrm{~min} .\end{array}$ & $\begin{array}{l}\text { (Randall } \\
\text { et al. } \\
\text { 2004) }\end{array}$ \\
\hline $\operatorname{mecA}$ & \multirow[t]{3}{*}{$\begin{array}{c}\text { Coagulase } \\
\text { Positive } \\
\text { Staphylococci }\end{array}$} & $\begin{array}{c}\text { GTAGAAATGACT } \\
\text { GAACGTCCGATA } \\
\text { A } \\
\text { CCAATTCCACATT } \\
\text { GTTTCGGTCTAA }\end{array}$ & $310 \mathrm{bp}$ & $\begin{array}{c}94^{\circ} \mathrm{C} \\
10 \mathrm{~min} .\end{array}$ & $\begin{array}{c}94^{\circ} \mathrm{C} \\
45 \mathrm{sec} .\end{array}$ & $\begin{array}{c}50^{\circ} \mathrm{C} \\
45 \mathrm{sec} .\end{array}$ & $\begin{array}{c}72^{\circ} \mathrm{C} \\
45 \mathrm{sec} .\end{array}$ & $\begin{array}{c}72^{\circ} \mathrm{C} \\
10 \mathrm{~min} .\end{array}$ & $\begin{array}{c}\text { (McClure } \\
\text { et al., 2006) }\end{array}$ \\
\hline tet $\mathrm{K}$ & & $\begin{array}{l}\text { GTAGCGACAATA } \\
\text { GGTAATAGT } \\
\text { GTAGTGACAATA } \\
\text { AACCTCCTA } \\
\end{array}$ & $360 \mathrm{bp}$ & $\begin{array}{c}94^{\circ} \mathrm{C} \\
10 \mathrm{~min} .\end{array}$ & $\begin{array}{c}94^{\circ} \mathrm{C} \\
45 \mathrm{sec} .\end{array}$ & $\begin{array}{c}55^{\circ} \mathrm{C} \\
45 \mathrm{sec} .\end{array}$ & $\begin{array}{c}72^{\circ} \mathrm{C} \\
45 \mathrm{sec} .\end{array}$ & $\begin{array}{c}72^{\circ} \mathrm{C} \\
10 \mathrm{~min} .\end{array}$ & \multirow[t]{2}{*}{$\begin{array}{l}\text { (Duran } \\
\text { et al., } \\
\text { 2012) }\end{array}$} \\
\hline blaZ & & $\begin{array}{c}\text { ACTTCAACACCTG } \\
\text { CTGCTTTC } \\
\text { TGACCACTTTTAT } \\
\text { CAGCAACC }\end{array}$ & $173 \mathrm{bp}$ & $\begin{array}{l}94^{\circ} \mathrm{C} \\
5 \mathrm{~min} .\end{array}$ & $\begin{array}{c}94^{\circ} \mathrm{C} \\
30 \mathrm{sec} .\end{array}$ & $\begin{array}{c}54^{\circ} \mathrm{C} \\
30 \mathrm{sec} .\end{array}$ & $\begin{array}{c}72^{\circ} \mathrm{C} \\
30 \mathrm{sec} .\end{array}$ & $\begin{array}{c}72^{\circ} \mathrm{C} \\
7 \mathrm{~min} .\end{array}$ & \\
\hline
\end{tabular}

Table 3: Isolation rates of detected E.coli serotypes:

\begin{tabular}{|c|c|c|c|c|c|}
\hline \multirow[t]{2}{*}{ Serotype } & \multicolumn{3}{|c|}{ Site of isolation } & \multirow{2}{*}{$\begin{array}{c}\text { Number of } \\
\text { isolates }\end{array}$} & \multirow[t]{2}{*}{ Isolation rate } \\
\hline & On the shell & content & $\begin{array}{l}\text { On the shell } \\
\text { and content }\end{array}$ & & \\
\hline Poly 2091 & 1 & $\mathbf{0}$ & $\mathbf{0}$ & 1 & $3 \%$ \\
\hline Poly 20125 & 2 & 1 & $\mathbf{0}$ & 3 & $8 \%$ \\
\hline Poly 20166 & 1 & $\mathbf{0}$ & $\mathbf{0}$ & 1 & $3 \%$ \\
\hline Poly 30145 & 1 & $\mathbf{0}$ & $\mathbf{0}$ & 1 & $3 \%$ \\
\hline Poly 406 & 2 & 1 & $\mathbf{0}$ & 3 & $8 \%$ \\
\hline Poly 4027 & 2 & 2 & 4 & 8 & $22 \%$ \\
\hline Poly 40159 & 2 & 1 & $\mathbf{0}$ & 3 & $8 \%$ \\
\hline Poly 5025 & 1 & $\mathbf{0}$ & $\mathbf{0}$ & 1 & $3 \%$ \\
\hline Poly 50153 & 1 & $\mathbf{0}$ & $\overline{\mathbf{0}}$ & 1 & $3 \%$ \\
\hline Poly 60115 & 1 & $\mathbf{0}$ & $\mathbf{0}$ & 1 & $3 \%$ \\
\hline Poly 60169 & $\mathbf{0}$ & 2 & 1 & 3 & $8 \%$ \\
\hline Poly 80152 & 2 & 1 & 1 & 4 & $11 \%$ \\
\hline poly 8029 & 1 & $\mathbf{0}$ & $\mathbf{0}$ & 1 & $3 \%$ \\
\hline Untypeable & 4 & 1 & $\mathbf{0}$ & 5 & $14 \%$ \\
\hline Total & 21 & 9 & 6 & 36 & $100 \%$ \\
\hline
\end{tabular}


Table 4: Antibiotic susceptibility pattern of E.coli isolates

\begin{tabular}{|c|c|c|c|c|c|}
\hline Antibiotic group & $\mathbf{S N}$ & Chemotherapeutic agent & $\begin{array}{c}\text { Susceptible } \\
\text { S }\end{array}$ & $\begin{array}{c}\text { Intermediate } \\
\text { I }\end{array}$ & $\begin{array}{c}\text { Resistant } \\
\text { R }\end{array}$ \\
\hline \multirow[t]{2}{*}{ penicillins } & 1 & Ampicillin (10 ug) & $33.3 \%$ & $\mathbf{0}$ & $66.7 \%$ \\
\hline & 2 & Amoxicillin (25ug) & $7.7 \%$ & $\mathbf{0}$ & $92.3 \%$ \\
\hline \multirow[t]{3}{*}{ Quinolones } & 3 & Ciprofloxacin (5ug) & $55.6 \%$ & $\mathbf{0}$ & $44.4 \%$ \\
\hline & 4 & Enrofloxacin (10ug ) & $29.4 \%$ & $2 \%$ & $68.6 \%$ \\
\hline & 5 & Norfloxacin (10ug) & $43.8 \%$ & $1.2 \%$ & $55 \%$ \\
\hline \multirow{3}{*}{ Aminoglycosedes } & 6 & Gentamycin (10 ug) & $59.8 \%$ & $\mathbf{0}$ & $40.2 \%$ \\
\hline & 7 & Kanamycin(20ug ) & $40 \%$ & $2 \%$ & $58 \%$ \\
\hline & 8 & Streptomycin (10 ug ) & $11.1 \%$ & $1.9 \%$ & $87 \%$ \\
\hline Polymyxins & 9 & Colistin(25 ug ) & $94.4 \%$ & $\mathbf{0}$ & $0.6 \%$ \\
\hline $\begin{array}{c}\text { Potentiated } \\
\text { Sulphonamides }\end{array}$ & 10 & $\begin{array}{c}\text { Trimethoprim- } \\
\text { sulphamethazole }(25 \mathrm{ug})\end{array}$ & $5.9 \%$ & $\mathbf{0}$ & $94.1 \%$ \\
\hline Cephalosporins & 11 & Cefotaxim (30 ug) & $76.5 \%$ & $1.5 \%$ & $22 \%$ \\
\hline Phenicols & 12 & $\begin{array}{c}\text { Chloramphinicol } \\
\text { (30 ug ) }\end{array}$ & $46.2 \%$ & $2 \%$ & $51.8 \%$ \\
\hline \multirow[t]{2}{*}{ Tetracyclines } & 13 & Tetracycline (30 ug ) & $7.1 \%$ & $\mathbf{0}$ & $92.9 \%$ \\
\hline & 14 & Doxycyclin (30 ug ) & $6.8 \%$ & $\mathbf{0}$ & $93.2 \%$ \\
\hline
\end{tabular}

Table 5: Antibiotic susceptibility pattern of Coagulase Positive Staphylococci isolates:

\begin{tabular}{|c|c|c|c|c|c|}
\hline Antibiotic group & $\mathbf{S N}$ & Chemotherapeutic agent & $\begin{array}{c}\text { Susceptible } \\
\text { I }\end{array}$ & $\begin{array}{c}\text { Intermediate } \\
\text { I }\end{array}$ & $\begin{array}{c}\text { Resistant } \\
\text { R }\end{array}$ \\
\hline \multirow[t]{3}{*}{ Penicillins } & 1 & Penecillin (10ug) & $42.3 \%$ & $1 \%$ & $56.7 \%$ \\
\hline & 2 & Ampicillin (10 ug) & $87 \%$ & $\mathbf{0}$ & $13.3 \%$ \\
\hline & 3 & Amoxicillin (25ug) & $66.7 \%$ & $\mathbf{0}$ & $33.3 \%$ \\
\hline $\begin{array}{c}\text { Anti-staphylococcal } \\
\beta \text {-lactams }\end{array}$ & 4 & Oxacillin (1ug) & $13.3 \%$ & $\mathbf{0}$ & $86.7 \%$ \\
\hline \multirow[t]{2}{*}{ Quinolones } & 5 & Ciprofloxacin (5ug) & $73.3 \%$ & $\mathbf{0}$ & $26.7 \%$ \\
\hline & 6 & Norfloxacin (10ug) & $63.2 \%$ & $2 \%$ & $34.8 \%$ \\
\hline \multirow[t]{3}{*}{ Aminoglycosides } & 7 & Gentamycin ( 10ug ) & $70 \%$ & $\mathbf{0}$ & $30 \%$ \\
\hline & 8 & Neomycin (30ug ) & $60 \%$ & $\mathbf{0}$ & $40 \%$ \\
\hline & 9 & $\begin{array}{c}\text { Streptomycin } \\
\text { (10 ug ) }\end{array}$ & $23.3 \%$ & $\mathbf{0}$ & $76.7 \%$ \\
\hline Macrolydes & 10 & Erythromycin (15ug) & $36.7 \%$ & $\mathbf{0}$ & $63.3 \%$ \\
\hline $\begin{array}{c}\text { Folate pathway } \\
\text { inhibitors }\end{array}$ & 11 & $\begin{array}{c}\text { Trimethoprim- } \\
\text { sulphamethazole }(25 \mathrm{ug})\end{array}$ & $13.3 \%$ & $\mathbf{0}$ & $86.7 \%$ \\
\hline Cephalosporins & 12 & Cefotaxim ( $30 \mathrm{ug}$ ) & $38 \%$ & $2 \%$ & $60 \%$ \\
\hline \multicolumn{6}{|l|}{ Phenicols } \\
\hline \multirow[t]{2}{*}{ Tetracyclines } & 14 & $\begin{array}{c}\text { Tetracyclines } \\
(30 \mathrm{ug})\end{array}$ & $20 \%$ & $\mathbf{0}$ & $80 \%$ \\
\hline & 15 & $\begin{array}{c}\text { Oxytetracyclin } \\
\text { (30 ug ) }\end{array}$ & $10 \%$ & $\overline{\mathbf{0}}$ & $90 \%$ \\
\hline
\end{tabular}


$\underline{\text { Assiut Vet. Med. J. Vol. } 61 \text { No } 144 \text { January } 2015}$

Table 6: PCR results of the different antibiotic resistance genes and antibiotic resistance profile of Coagulase Positive Staphylococci.

\begin{tabular}{|c|c|c|c|c|c|c|}
\hline CPS & & & & & & \\
\hline Isolate code & bla Z & Penicillin & $\operatorname{mec} \mathrm{A}$ & Oxacillin & tetK & Tetracycline \\
\hline Z13 & - & $\mathbf{R}$ & - & $\mathbf{R}$ & + & $\mathbf{R}$ \\
\hline 33 & - & $\mathbf{R}$ & - & $\mathbf{R}$ & + & $\mathbf{R}$ \\
\hline E85 & + & $\mathbf{R}$ & + & $\mathbf{R}$ & + & $\mathbf{R}$ \\
\hline 31 & + & $\mathbf{R}$ & + & $\mathbf{R}$ & + & $\mathbf{R}$ \\
\hline 23 & - & $\mathbf{S}$ & - & $\mathbf{S}$ & + & $\mathbf{S}$ \\
\hline Z6 & - & $\mathbf{R}$ & - & $\mathbf{R}$ & - & $\mathbf{R}$ \\
\hline H4 & - & $\mathbf{S}$ & - & $\mathbf{R}$ & - & $\mathbf{R}$ \\
\hline H34 & + & $\mathbf{R}$ & + & $\mathbf{R}$ & + & $\mathbf{R}$ \\
\hline E58 & + & $\mathbf{R}$ & + & $\mathbf{S}$ & + & $\mathbf{R}$ \\
\hline E103 & + & $\mathbf{R}$ & - & $\mathbf{R}$ & - & $\mathbf{R}$ \\
\hline 88 & + & $\mathbf{R}$ & - & $\mathbf{R}$ & + & $\mathbf{R}$ \\
\hline $\begin{array}{c}\text { Pos PCR \% } \\
\text { or antibiotic resistance } \\
\%\end{array}$ & 54.54 & 81.81 & 36.36 & 81.81 & 72.72 & 90.9 \\
\hline
\end{tabular}

Table 7: PCR results of the different virulence genes of the CPS isolates.

\begin{tabular}{|c|c|c|c|c|c|c|c|c|}
\hline $\begin{array}{c}\text { CPS } \\
\text { isolate }\end{array}$ & Sea & Seb & Sec & Sed & See & spa & Coa & hlg \\
\hline Z13 & - & - & - & - & - & + & + & - \\
\hline 33 & - & & + & - & + & + & + & + \\
\hline E85 & - & + & - & - & - & + & + & + \\
\hline 31 & - & + & + & - & - & + & + & + \\
\hline 23 & - & + & + & - & - & + & + & - \\
\hline Z6 & - & - & - & - & - & - & + & - \\
\hline H4 & - & - & + & - & - & - & + & - \\
\hline H34 & - & - & + & - & + & + & + & + \\
\hline E58 & - & + & - & - & + & + & + & + \\
\hline E103 & - & - & - & - & - & + & + & - \\
\hline 88 & - & + & - & - & - & + & + & - \\
\hline Pos \% & 0 & 45.45 & 45.45 & 0 & 27.27 & 81.81 & 100 & 45.45 \\
\hline
\end{tabular}


$\underline{\text { Assiut Vet. Med. J. Vol. } 61 \text { No } 144 \text { January } 2015}$

Table 8: PCR results of the different antibiotic resistance genes and antibiotic resistance profile of E. coli.

\begin{tabular}{c|c|c|c|c|c|c}
\hline \multicolumn{7}{c}{ E. coli } \\
\hline Isolate code & ${ }^{b l a}$ TEM & Amoxicillin & Sul1 & $\begin{array}{c}\text { Trimethoprim- } \\
\text { sulphamethazole }\end{array}$ & tetA(A) & Tetracycline \\
\hline E49 & + & $\mathbf{R}$ & - & $\mathbf{S}$ & + & $\mathbf{R}$ \\
\hline E4 & + & $\mathbf{S}$ & + & $\mathbf{S}$ & + & $\mathbf{S}$ \\
\hline T2 & + & $\mathbf{R}$ & + & $\mathbf{R}$ & + & $\mathbf{R}$ \\
\hline E30 & + & $\mathbf{R}$ & + & $\mathbf{R}$ & + & $\mathbf{R}$ \\
\hline E22 & + & $\mathbf{R}$ & - & $\mathbf{R}$ & + & $\mathbf{R}$ \\
\hline Z9 & + & $\mathbf{R}$ & - & $\mathbf{R}$ & + & $\mathbf{R}$ \\
\hline Z18 & + & $\mathbf{R}$ & + & $\mathbf{R}$ & + & $\mathbf{R}$ \\
\hline Z13 & + & $\mathbf{R}$ & + & $\mathbf{R}$ & + & $\mathbf{R}$ \\
\hline H3 & + & $\mathbf{R}$ & - & $\mathbf{R}$ & + & $\mathbf{R}$ \\
\hline E31 & + & $\mathbf{R}$ & + & $\mathbf{R}$ & + & $\mathbf{R}$ \\
\hline E21 & + & $\mathbf{R}$ & + & $\mathbf{R}$ & + & $\mathbf{R}$ \\
\hline E23 & - & $\mathbf{R}$ & - & $\mathbf{R}$ & + & $\mathbf{R}$ \\
\hline E47 & + & $\mathbf{R}$ & + & $\mathbf{R}$ & + & $\mathbf{R}$ \\
\hline $\begin{array}{l}\text { Pos PCR \% } \\
\text { or antibiotic } \\
\text { resistance \% }\end{array}$ & $\mathbf{9 2 . 3}$ & $\mathbf{9 2 . 3}$ & $\mathbf{6 1 . 5 3}$ & $\mathbf{8 4 . 6 1}$ & $\mathbf{1 0 0}$ & $\mathbf{9 2 . 3}$ \\
\hline
\end{tabular}

Table 9: PCR results of the different virulence genes of the E. coli isolates.

\begin{tabular}{|c|c|c|c|c|c|c|}
\hline E. coli isolate & tsh & iss & Stx 1 & Stx 2 & eaeA & papC \\
\hline E49 & + & + & - & - & + & - \\
\hline $\mathbf{E 4}$ & - & + & - & + & + & - \\
\hline $\mathbf{T} 2$ & - & + & - & + & + & - \\
\hline E30 & + & + & - & + & + & - \\
\hline E22 & - & + & - & - & + & + \\
\hline $\mathbf{Z 9}$ & + & + & - & - & + & + \\
\hline Z18 & + & - & - & - & + & - \\
\hline Z13 & - & + & - & - & + & - \\
\hline H3 & - & + & - & + & + & - \\
\hline E31 & - & + & - & - & + & - \\
\hline E21 & - & - & - & - & + & + \\
\hline E23 & - & - & - & - & + & - \\
\hline $\mathbf{E 4 7}$ & - & + & - & + & + & - \\
\hline $\operatorname{Pos} \%$ & 30.76 & 76.92 & 0 & 38.46 & 100 & 23.07 \\
\hline
\end{tabular}




\section{DISCUSSION}

Eggs produced from backyard house hold chickens in Egyptian villages are commonly used for own consumption or to be sold in local markets, ( most commonly used unwashed).

Special attention has been paid for raw or undercooked eggs because the hens act as natural reservoirs of a variety of pathogens. The contamination occurs through the shell; But humidity, temperature and storage time are critical for migration of bacteria from the surface of the shell to the inner structures of the egg (Evêncio et al., 2012).

In the present study 200 eggs produced from backyard chickens were examined for the presence of Salmonella spp., E.coli, and Coagulase Positive Staphylococci.

The study detected no Salmonella neither from on the shell nor from the egg contents. Although many researchers have reported similar results as (Chousalkar et al., 2010), higher isolation rates of Salmonella spp. were reported by other researcher as (Mona et al., 2014) who detected Salmonella in eggs at a rate of $(1.5 \%)$. However, (Camilleri, 1992) stated that failure to detect salmonella spp. from eggs does not imply that local flocks are not infected by salmonella.

The study declared a total of 36 E.coli isolates with an overall prevalence rates of $18 \%$. Among the total isolates, $21(10.5 \%)$ isolates, $9(4.5 \%)$ isolates, and $6(3.0 \%)$ isolates were detected from over the shell, egg contents, and both shell and contents, respectively. Almost similar results were reported by (Arathy et al., 2011) they could detect an overall isolation rate of $12.2 \%$, while $8 \%$ of the isolates were detected from shell and 5\% from yolk samples, respectively. Higher isolation rate was reported by (Adesiyun et al., 2005) who recorded (37.0\%) as an overall isolation rate, $(28.3 \%)$ as an isolation rate from egg shell, while they recorded almost similar isolation rate from egg content samples (3.8\%). Lower isolation rates were recorded by (Saitanu et al.,1994) who isolated E.coli from egg shells and in egg contents with a rate of $3.5 \%$ and $1.2 \%$, respectively.

Coagulase Positive Staphylococci including Staphylococcus aureus and other spp. are important Pathogens in human and veterinary medicine, beside their importance in regard to food hygiene because of their ability to form staphylococcal enterotoxins (SEs). The present study applied (ISO 6888-1:1999, AM: 2003) which specifies enumeration and detection of Coagulase Positive Staphylococci "among which enterotoxigenic strains are encountered" in products intended for human consumption or feeding of animals. Rosa et al.
(2001) Suggested that Baird Parker is sufficient to screen the presence of Staphylococcus aureus without the need for further identification, resulting in saving time and money. The study investigated eggs for the presence of Coagulase Positive Staphylococci both on the shell and in the contents, 80 isolates were detected with an overall prevalence rate of $40 \%$. Isolation rates were $29(14.5 \%), 15$ $(7.5 \%)$, and $36(18 \%)$ from on the shell, contents, and both shell and contents, respectively. Higher prevalence rates were recorded by (Stepień et al., 2009) when they reported the isolation of Coagulase Positive Staphylococci from eggs with a rate of $45.7 \%$, of which $2.5 \%, 38.7 \%$, and $58.8 \%$ were detected from white, yolk, and on the shell, respectively.

In the present study, out of the 200 examined eggs 15 (7.5\%) harbored both E.coli and Coagulase Positive Staphylococci. This result was in agreement with that stated by (Obi and Igbokwe, 2009) who were able to reveal that freshly laid and stored domestic fowl eggs were contaminated by consortia of microorganisms, which migrated and invaded the inner parts of the eggs due to primarily heavy contamination and then prevailing poor storage conditions.

Serotypes of E. coli are classified according to the Kauffmann scheme, currently there are approximately $180 \mathrm{O}, 60 \mathrm{H}$ and $80 \mathrm{~K}$ antigens; The numbers change as new ones are identified and previous ones that are duplicated or attributable to another bacterial species are removed, additional serotypes with $\mathrm{O}$ antigens that have not been recognized also are found in most surveys. Even though molecular methods for identifying specific virulence genes are available, serotyping remains a useful tool for epidemiologic studies. Serotyping provides a means of relating previous work with new work. Variations in the distribution of serotypes according to geographic region occur. Many other serotypes have been found less frequently, while some APEC do not belong to known serotypes or are untypeable (Swayne, 2013). In the present study,13 serotypes belonged to 6 different $\mathrm{O}$ groups were identified, of which $\mathrm{O} 27$ predominated with an isolation rate of (22\%), followed by $\mathrm{O} 152$ (11\%).While, O125, O6, O159 and O169 were isolated with a rate of (8\%), each. Finally, each of O91, O166, O145, O25, O153, O115, and O29 was isolated with a rate of (3\%). Serotyping with the available kits failed to identify 5 isolates $(14 \%)$. The result of serotyping agreed with that of (Rosario et al., 2004) who failed to identify the serogroups of $15 \%$ of isolates.

In the present study, antibiotic susceptibility patterns of E.coli and Coagulase Positive Staphylococci isolates were studied. The study revealed the prevalence of MDR isolates among both microorganisms. The study recorded that $34(94.1 \%)$, 
and $72(90 \%)$ of E.coli, and Coagulase Positive Staphylococci isolates, respectively were considered MDR ; As it was observed that the tested isolates were resistant to 5 and more; And 3 and more antimicrobial drugs, respectively. Also those drugs belonged to different antimicrobial categories. The result was in accordance with (CLSI, 2011) where it was reported that MDR was defined as acquired nonsusceptibility to at least one agent in three or more antimicrobial categories.

The study recorded that $94.1 \%$ of E.coli isolates were resistant to 5 and more antimicrobial drug from varying drug category. This result agreed with that of (Muhammad et al., 2009) who reported the detection of MDR E.coli with a rate of $100 \%$. The highest resistance rates were recorded against Trimethoprimsulphamethazole, doxycyclin, tetracycline, and amoxicillin; 94.1\%, 93.2\%, 92.9\%, and $92.3 \%$, respectively. While the highest sensitivity rates were detected to colistin, cefotaxim, gentamycin, and ciprofloxacin; $94.4 . \%, 76.5 \% 59.8 \%$, and $55.6 \%$, respectively.

The result for trimethoprim- sulphamethazole susceptibility was similar to that of (Li et al., 2007) as they recorded resistance rate of $100 \%$. While lower resistance rate was observed by (Hasan et al., 2011) who reported resistance rate of $26.7 \%$.

Concerning resistance rate against doxycyclin, the result of this study was almost similar to that detected by (Jiang et al., 2009) who reported resistance rate of $95.6 \%$.

The results for resistance profiles against tetracycline were in agreement with that of (Jiang et al., 2009) who reported resistance rate of 93.4\%. Lower resistance rate was recorded by (Muhammad et al., 2009) who recorded $52 \%$.

The study of resistance rate against amoxicillin was in agreement with that of (Sheikh et al., 2012) who reported a rate of $92.86 \%$, lower resistance rate was recorded by (Motayo et al., 2013) who recorded a resistance rate of $16.8 \%$.

The result of colistin sensitivity agreed with the result of (Maalej et al., 2011) who observed sensitivity rate to colistin of $100 \%$.

The result of susceptibility concerning cefotaxim was in accordance with that of (Pérez et al., 2014) who recorded resistance rate of $84.5 \%$. In the contrary Oteo et al. (2006) recorded resistance rate of $100 \%$.

The result of gentamycin was in agreement with that of (Huang et al., 2009) who detected sensitivity rate of $55.96 \%$.

Higher susceptibility rate to ciprofloxacin was detected by (Hasan et al., 2011) who reported a sensitivity rate of $87.1 \%$. On the other hand, lower resistance rate was recorded by (Li et al., 2007) who recorded $19 \%$.

The study revealed that 72 (90\%) of Coagulase Positive Staphylococci isolates were considered MDR. This result was in agreement with that of (Suleiman et al., 2013) who reported that $100 \%$ of the detected Coagulase Positive Staphylococci isolates were MDR.

The study revealed that the highest sensitivity rate of Coagulase Positive Staphylococci was observed against ampicillin $87 \%$. This result disagreed with that of (Lee, 2003) who recorded resistance rate of $73.3 \%$.

The antibiotic susceptibility profile of Coagulase Positive Staphylococci isolates revealed $73.3 \%$ sensitivity rate to ciprofloxacin. This result was in accordance with that of (Suleiman et al., 2013) who detected sensitivity rate of $100 \%$.

The detected sensitivity rate to gentamycin was $70 \%$. This result was in agreement with that of (Suleiman et al., 2013) who observed sensitivity rate of $100 \%$.

The study detected that the highest resistance rate of Coagulase Positive Staphylococci was against oxytetracyclin $90 \%$, this result agreed with that of (El-Jakee et al., 2008) who observed resistance rate against oxytetracyclin of $80 \%$.

The study also observed $86.7 \%$ resistance rate of Coagulase Positive Staphylococci against trimethoprime-sulphamethazone. This result disagreed with that of (Lee, 2003) who succeeded to detect $100 \%$ sensitivity rate for trimethoprimesulphamethazone. On the other hand, the result was in accordance with that of (Nam et al., 2011) who detected resistance rate of $100 \%$.

The observed resistance rate of Coagulase Positive Staphylococci against oxacillin was $86.7 \%$.This result was similar to that of (Lee, 2003) who detected $100 \%$ resistance rate against oxacillin. While, this result disagreed with that of (Nam et al., 2011) who detected resistance rate against oxacillin of (6.2\%).

Control programs do not address laying hens whose eggs are produced for personal consumption or local sale, control measures should not forget home-produced eggs, as there is a risk of infection from their consumption, (Hardy et al., 2012).

The eaeA gene was tested to speculate the virulence of the isolated E. coli strains. There were $100 \%$ positive results for this gene. This result assured the virulence of these isolates because the eaeA gene encodes for intimin protein which is considered as a bacterial adhesion molecules that leads to the emersion of the A/E lesions (Kilici et al., 2007). The high incidence rate of eaeA gene detection was recorded by many authors as (El-Jakee et al., 2012) 
who detected eaeA gene in $95.9 \%$ of the tested E. coli $\mathrm{O} 157: \mathrm{H} 7$ isolates.

The iss gene had the 2nd incidence degree as $76.92 \%$ of the E. coli isolates showed positive amplification of the specific $266 \mathrm{bp}$ of this gene. Iss (increased serum survival gene) is considered as a promising virulence gene that is usually associated with the APEC strains. Its rule was studied by (Lynne et al., 2007) when they observed a significant drop in E. coli resistance to serum with the iss- mutant. A bormutant also showed a drop in serum resistance but the drop in serum resistance was more violent in issmutant which indicates that iss contributes more to serum resistance than bor in the E. coli strains. This effect was assured when the level of serum resistance was restored after the iss was reintroduced into the iss- mutant.

The $t s h$ (temperature-sensitive hemagglutinin) gene was detected in 4 isolates. This gene encodes for an autotransporter protein secreted by avian-pathogenic E. coli. This gene is rarely detected in commensal E. coli (Delicato et al., 2002) and is frequently found in highly pathogenic avian E. coli. The presence of this gene increases the danger of the harboring strains as it has a potential role as an adhesin (Provence \& Curtiss, 1994) and it also has the ability to degrade haemoglobin (Otto et al., 1998).

None of the thirteen tested E. coli isolates showed positive PCR results for the stx 1 gene. However, 5 isolates $(38.46 \%)$ was recorded as positive for the stx 2 gene. A close result was reported by (Zahraei et al., 2007) who suggested that Stx2 may be widespread among APEC as they detected st 1 only in one isolate $(8.33 \%)$ out of the 12 tested isolates, but stx 2 was detected in $9(75 \%)$ isolates. ALAshmawy, (2013) has much correlated results as she detected stx 2 in $37 / 39$ of the E. coli isolates from table eggs. The correlation was high also because none of the positive stx 2 isolates showed positive results for stx1 gene. The heat stable toxin (Stx) causes disruption of chloride channels in the cell and secretion of fluid and electrolytes into the intestinal lumen causing diarrhea (Gaastra and Svennerholm, 1996). However the current results differed markedly from that obtained by many authors as (Wani et al., 2004; Zahraei et al., 2007 and AL-Ashmawy, 2013) who reported that all stx 2 positive isolates were negative for eae genes, our results were supported by that obtained by (Dutta et al., 2011) who recorded eae and stx 1 genes in 2 toxin producing Escherichia coli (STEC) isolates. The results of the current study also was supported by the study done in Egypt by (Galal et al., 2013) who detected both of the stx1 and stx2 genes with eaeA gene in $2 / 19(10.52 \%)$ of the samples, and detected either stx 1 or stx 2 with eae A gene in $3 / 19(15.78 \%)$ of the samples.

The pap $\mathrm{C}$ gene which encodes for the $\mathrm{P}$ fimbriae was detected in 3 isolates. Rocha et al. (2008) reported that papC operon is located in bacterial colonization in respiratory epithelium which directly affects the intensity of infection.

The gamma haemolysine ( $h l g$ ) gene was positively amplified in $45.45 \%$ of the tested Coagulase Positive Staphylococci isolates. This gene is considered as one of the most important virulence genes of Staphylococci as it lead to generation of pores in the erythrocytes after initial binding of the two synergistically acting proteins $h \lg \mathrm{B}$ and $h l g \mathrm{~A}$ (Dickinson and Bisno, 1993).

The risk of Coagulase Positive Staphylococci isolates was accounted through the $81.81 \%$ positive percentage of the spa gene. This gene encodes for the protein A which antagonize the function of the immune system through hindering of the antibody mediated immune clearance of the organism through binding to the Fc receptor of IgG. Also, protein A interferes with the phagocytosis of opsonized bacteria via binding IgG (Murray et al., 2002).

The PCR result of the coa gene was enough to confirm the virulence of the Staphylococci isolates as it is considered as a marker for its virulence. The coagulase aids in the formation of a fibrin layer around a focal staphylococcal abscess, which leads to the localization of the infection and protecting the organism from phagocytosis (Sawai et al., 1997).

The results of the enterotoxin genes were so interesting, as $45.45 \%$ of the isolates were positive for $\mathrm{Seb}$ and $\mathrm{Sec}$, while $27.27 \%$ of the isolates showed positive results for the See gene. The presence of these entrotoxins is so threatening as they resist the hydrolysis by gastric and jejunal enzymes and also they are heat stable at $100^{\circ} \mathrm{C}$ for 30 minutes which can explain why the staphylococcal food poisoning is the leading cause of food-borne microbial intoxication worldwide (Holmberg and Blake, 1984).

The blaTEM gene was tested for the 11 selected E. coli isolates to assess its resistance to amoxicillin. Interestingly, the positive PCR percent $(92.3 \%)$ was highly related to the phenotypic positive percent $(92.3 \%)$ which confirmed the high degree of the resistance of these isolates to amoxicillin.

However, the PCR showed high positivity for the TetA(A) gene $(100 \%)$ than the positive resistance percent obtained for the tetracycline by the antibiotic susceptibility test $(92.3 \%$ ), which may be related to the sensitivity of PCR itself. This also may be related to the antibiotic susceptibility test which may be influenced by several factors, some of which include the medium used for bacterial culture, type of drug tested, and the type of organism.

Conversely, the antibiotic susceptibility test showed higher positive percent for the trimethoprimsulphamethazole $(84.61 \%)$ than that showed for sul 1 gene by PCR $(61.53 \%)$. This was elucidated by 
(Gündoğdu et al., 2011) who recorded 10 strains of 96 carrying sul2 and intl 1 were not positive for the presence of the sul1 gene. This was explained by (Grape et al., 2005) who referred to the sul1 gene as a semi-conserved segment.

Out of the 11 tested Staphylococci isolates, 4 were positive for mecA gene. This can increase the ferocity of this isolates. This was also reported by (Pyzik et al., 2014) who detected mecA gene in two S. aureus-like strains isolated from table eggs. To determine the ability of MRSA strains to infect human, (Lee, 2003) performed RAPD PCR and the results showed that their genome was very closely related to some human strains considering these isolates may be a possible source of food borne human infections.

However, the PCR positive percent for mecA gene $(36.36 \%)$ was somewhat far from that obtained by antibiotic susceptibility test which showed $81.81 \%$ positive percent for the resistance to oxacillin. This was clarified by (Mathews et al., 2010) who reported two types of strains that show phenotypic resistance to oxacillin however they don't harbor the mecA gene. The 1st type of those two strains is called borderline oxacillin resistant S.aureus (BORSA) which hyper produces betalactamase and while they appear oxacillin resistant, do not possess the usual genetic mechanism for such resistance. They reported also that another type of strains known as modified S. aureus (MODSA) which possess a modification of existing penicillin binding proteins rather than the acquisition of a new PBP as is the mechanism for classical MRSA.

The tet $\mathrm{K}$ gene was tested for the evaluation of the antibiotic resistance to tetracycline. The PCR result showed a $72.72 \%$ positive result which was lower than the resistance percent encountered by the antibiotic susceptibility test $(90.9 \%)$. Schmitz et al. (2001) illustrated the mechanisms of tetracycline resistance for Staphylococcus species in two models. The 1 st one is the active efflux resulting from the acquisition of the tet $\mathrm{K}$ and $t e t \mathrm{~L}$ genes located on a plasmid; and the 2nd one is the ribosomal protection mediated by tet $\mathrm{M}$ or tet $\mathrm{O}$ determinants located on either a transposon or the chromosome. And as recorded by (Duran et al., 2012), the tet $\mathrm{M}$ gene had higher positive percent $(78 \%)$ than that recorded for tet $\mathrm{K}(43 \%)$ in the study performed to evaluate the association between the antibiotic susceptibility patterns and the antibiotic resistance genes in staphylococcal isolates.

The blaZ gene was positively amplified in $54.54 \%$ of the Staphylococci isolates. This result was dissimilar to the recorded penicillin resistance by the antibiotic susceptibility test $(81.81 \%)$. The discrepancy between those results may also be related to the different mechanisms (other than blaZ) for the resistance of staphylococci to penicillins. Duran et al.
(2012) mentioned those 2 mechanisms where the most important mechanism one is the production of beta-lactamase which inactivates penicillin by hydrolysis of its beta-lactam ring, another mechanism is associated with penicillin-binding protein $2 \mathrm{a}(\mathrm{PBP} 2 \mathrm{a})$, encoded by mecA.

In conclusion, this study confirm that local house hold produced chicken eggs which are consumed as food can harbor resistant bacterial pathogen of zoonotic importance, those pathogens may impose public health hazard. The study recommends rising public awareness to the importance of proper thermal processing and cooking of eggs specially for immune-compromised group as pregnant women, children and old ages. The study also recommends regular monitoring and surveillance of house hold sector together with guidance programs to the public targeting rising awareness for safe house hold rearing procedures of chicken, storage and handling of eggs, in order to prevent dissemination of dangerous pathogens through environment and the transfer of infection to other animals and human.

\section{REFERENCE}

Abulreesh, HH. and Organji, SR. (2011): The Prevalence of Multidrug-resistant Staphylococci in Food and the Environment of Makkah, Saudi Arabia. Res. J. Microbiol. 6: 510-523.

Adesiyun, A.; Offiah, N.; Seepersadsingh, N.; Rodrigo, $\quad$ S.; Lashley, $\quad$ V.; Musai, $\quad L$. and Georges, K. (2005): Microbial health risk posed by table eggs in Trinidad.Epidemiol Infect. 2005 Dec; 133(6): 1049-56.

Ahmed, M.M.; Rahman, M.M.; Mahbub, K.R. and Wahiduzzaman, M. (2011): Characterization of Antibiotic Resistant Salmonella spp Isolated from Chicken Eggs of Dhaka City .J. Sci. Res. 3 (1), 191-196 (2011). doi: 10.3329/jsr.v3i1.6109.

AL-Ashmawy, M.A.M. (2013): Prevalence of Enterobacteriaceae in Table Eggs with Particular Reference to Enterovirulent Escherichia coli Strains. International Journal of Poultry Science 12 (7): 430-435, 2013.

Arathy, DS.; Vanpee, G.; Belot, G.; Mathew, V.; DeAllie, $\quad C$. and Sharma, R. (2011): Antimicrobial drug resistance in Escherichia coli isolated from commercial chicken eggs in Grenada, West Indies. West Indian Med. J. 2011 Jan; 60(1): 53-6.

Barbara Ingham and Ron Kean (2010): Egg Safety and the Backyard Flock University of Wisconsin-Madison and University of Wisconsin-Extension Adapted with permission from Home-Produced Chicken Eggs (Colorado State University Extension bulletin no. 9.377 (updated 5/12/2010)) by M. Bunning and J. Avens. For information, 
contact Dr. Barbara Ingham bhingham@wisc.edu or Ron Kean at rpkean@wisc.edu 1/2011.

Bauer, A.W.; Kirby, W.M.M.; Sheris, J.C. and Truk, M. (1966): Antibiotic susceptibility testing by a standardized single disc method. American J. Clinical Pathol., 145: 225/230.

Camilleri, F. (1992): Incidence of salmonellosis in local hens' eggs. J R Soc Health. 1992 Oct; 112(5): 212-3.

Casey, AL.; Lambert, PA. and Elliot, T.S.J. (2007): Staphylococci. International Journal of Antimicrobial Agents, 29, 23-32.

Chousalkar, KK.; Flynn, P.; Sutherland, M.; Roberts, JR. and Cheetham, BF. (2010): Recovery of Salmonella and Escherichia coli from commercial egg shells and effect of translucency on bacterial penetration in eggs. Int. J. Food Microbiol. 2010 Aug 15;142(1-2): 207-13.doi:10.1016/j.ijfoodmicro. 2010.06.029. Epub 2010 Jul 3.

CLSI, (Clinical and Laboratory Standards Institute 2011): Performance Standards for Antimicrobial Susceptibility Testing; Twenty First Informational Supplement, M100S21, standard by Clinical and Laboratory Standards Institute, 01/01/2011.

Colom, K.; Pèrez, J.; Alonso, R.; FernándezAranguiz, A.; Lariňo, E. and Cisterna, R. (2003): Simple and reliable multiplex PCR assay for detection of $b l a_{\mathrm{TEM}}, b l a_{\mathrm{SHV}}$ and $b l a_{\mathrm{OXA}-1}$ genes in Enterobacteriaceae. FEMS Microbiology Letters 223 (2003) 147-151.

Delicato, E.R.; de Brito, B.G.; Gaziri, L.C.J. and Vidotto, M.C. (2003): Virulence-associated genes in Escherichia coli isolates from poultry with colibacillosis. Veterinary Microbiology 94 (2003) 97-103.

Delicato, E.R.; de Brito, B.G.; Konopatzki, A.P.; Gaziri, L.C.J. and Vidotto, M.C. (2002): Occurrence of the temperature-sensitive hemagglutinin among avian Escherichia coli. Avian Diseases, 46, 713-716.

Dickinson, M. and Bisno, A.L. (1993): Infections associated with prosthetic devices: clinical considerations. Int. J. Artif. Organs 16: 749-754.

Dipineto, L.; Santaniello, A.; Fontanella, M.; Lagos, K.; Fioretti, A. and Menna, L.F. (2006): Presence of Shiga toxin-producing Escherichia coli O157:H7 in living layer hens. Letters in Applied Microbiology 43 (2006) 293-295.

Duran, N.; Ozer, B.; Duran, G.G.; Onlen, Y. and Demir, C. (2012): Antibiotic resistance genes \& susceptibility patterns in staphylococci. Indian J. Med. Res. 135, March 2012, pp 389-396.

Dutta, T.K.; Roychoudhury, P.; Bandyopadhyay, S.; Wani, S.A. and Hussain, I. (2011): Detection
\& characterization of Shiga toxin producing Escherichia coli (STEC) \& enteropathogenic Escherichia coli (EPEC) in poultry birds with diarrhea. Indian J Med Res 133, May 2011, pp 541-545.

El-Jakee, J.; Ata S. Nagwa; M. Bakry; Sahar A. Zouelfakar; Elgabry, E. and Gad El-Said, 1W.A. (2008): Characteristics of Staphylococcus aureus Strains Isolated from Human and Animal Sources. AmericanEurasian J. Agric. \& Environ. Sci., 4 (2): 221 229, 2008. ISSN 1818-6769@ IDOSI Publications, 2008.

El-Jakee, J.K.; Mahmoud, R.M.; Samy, A.A.; ElShabrawy, M.A.; Effat, M.M. and Gad ElSaid, W.A. (2012): Molecular Characterization of E. coli Isolated from Chicken, Cattle and Buffaloes. International Journal of Microbiological Research 3 (1): 64-74.

Evêncio-Luz, L.; Lima-Filho, J.V. and Evêncio-Neto, J. (2012): Occurrence of Salmonella sp. and coagulase-positive staphylococci in raw eggs and Coalho cheese: comparative study between two cities of Brazil's northeast. Braz J Microbiol. 2012 Oct-Dec; 43(4): 1463-1466. doi: $10.1590 / \mathrm{S} 1517-838220120004000030$.

Gaastra, W. and Svennerholm, A.M. (1996): Colonization factors of human enterotoxigenic Escherichia coli (ETEC). Trends Microbiol., 4: 444-452.

Galal, H.M.; Hakim, A.S. and Dorgham, S.M. (2013): Phenotypic and virulence genes screening of Escherichia coli strains isolated from different sources in delta Egypt. Life Science Journal, 2013;10(2).

Grape, M.; Farra, A.; Kronvall, G. \& Sundström, L. (2005): Integrons and gene cassettes in clinical isolates of co-trimoxazole-resistant Gram-negative bacteria. Clin Microbiol Infect 11, 185-192.

Gündoğdu, A.; Long, Y.B. Vollmerhausen, T.L. and Katouli, M. (2011): Antimicrobial resistance and distribution of sul genes and integronassociated intI genes among uropathogenic Escherichia coli in Queensland, Australia. Journal of Medical Microbiology (2011), 60, 1633-1642.

Hardy Zielicka, A.; Zarowna, D.; Szych, J.; Madajczak, G. and Sadkowska-Todys, M. (2012): Ensuring safety of homeproduced eggs to control salmonellosis in Poland: lessons from an outbreak in September 2011. Euro Surveill. 2012 Nov 22;17(47). pii: 20319.

Hasan, B.; Faruque, R.; Drobni, M.; Waldenström, J.; Sadique, A.; Ahmed, K.U.; Islam, Z.; Parvez, M.B.; Olsen, B. and Alam, M. (2011): High prevalence of antibiotic resistance in pathogenic Escherichia coli from large- and 
small-scale poultry farms in Bangladesh. Avian Dis. 2011 Dec; 55(4): 689-92.

Holmberg, S.D. and Blake, P.A. (1984): Staphylococcal food poisoning in the United States. new facts and old misconceptions. JAMA 251: 487-489.

Huang, TM.; Lin, TL. and Wu, CC. (2009): Antimicrobial susceptibility and resistance of chicken Escherichia coli, Salmonella spp., and Pasteurella multocida isolates. Avian Dis. 2009 Mar; 53(1): 89-93.

Ibekwe, A.M.; Murinda, S.E. and Graves, A.K. (2011): Genetic Diversity and Antimicrobial Resistance of Escherichia coli from Human and Animal Sources Uncovers Multiple Resistances from Human Sources. PLoS ONE, Volume 6, Issue 6, e20819.

ISO 6579: (2002), COR: (2004): Microbiology of food and animal feeding stuffs- Horizontal method for the detection of Salmonellaspp. 4th Edition. www.iso.org/iso.

ISO 6888-1: (1999), AM:(2003): Microbiology of food and animal feeding stuffs - Horizontal method for the enumeration of coagulasepositive staphylococci (Staphylococcus aureus and other species).

Iyer, A.P. and Kumosani, T.A. (2011): PCR based detection of nosocomial infection causing MRSA (Methicillin resistant Staphylococcus aureus). 2011 2nd International Conference on Biotechnology and Food Science IPCBEE vol.7 (2011) @ (2011) IACSIT Press, Singapore.

Jiang, HX.; Lü, DH.; Chen, ZL.; Wang, XM.; Chen, JR.; Liu, YH.; Liao, XP.; Liu, JH. and Zeng, ZL. (2009): High prevalence and widespread distribution of multi-resistant Escherichia coli isolates in pigs and poultry in China. Vet J. Zx Jan;187(1): 99-103. doi: 10.1016/j.tvj1.2009. 10.017. Epub 2009 Nov 18.

Kilici, A.; Ertas, H.B.; Muz, A.; özbey, G. and Kalender, H. (2007): Detection of the eaeA Gene in Escherichia coli from Chickens by Polymerase Chain Reaction. Turk. J. Vet. Anim. Sci. 2007; 31(4): 215-218.

Kreig N.R.; J.G. Holt; Williams and Wilkins, (1984): Bergeys Manual of Systematic Bacteriol., 1:428, East Preston street, Baltimor, M.D.21202, USA.

Kumar, JD.; Negi, YK.; Gaur, A. and Khanna, D. (2009): Detection of virulence genes in Staphylococcus aureus isolated from paper currency. International Journal of Infectious Diseases 13: e450-e455.

Lee Hwa John, (2003): Methicillin (Oxacillin)Resistant Staphylococcus aureus Strains Isolated from Major Food Animals and Their Potential Transmission to Humans. Appl Environ Microbiol. Nov 2003; 69(11): 6489-
6494. doi: 10.1128/AEM.69.11.64896494.2003

Li, X.S.; Wang, G.Q.; Du, X.D.; Cui, B.A.; Zhang, S.M. and Shen, J.Z. (2007): Antimicrobial susceptibility and molecular detection of chloramphenicol and florfenicol resistance among Escherichia coli isolates from diseased chickens. J. Vet. Sci. 2007 Sep; 8(3): 243-7.

Lynne, A.M.; Skyberg, J.A.; Logue, C.M.; Doetkott, C.; Foley, S.L. and Nolan, L.K. (2007): Characterization of a series of transconjugant mutants of an avian pathogenic Escherichia coli isolate for resistance to serum complement. Avian Dis. 2007 Sep;51(3): 771-6.

Maalej, SM.; Meziou, MR.; Rhimi, FM. and Hammami, A. (2011): Comparison of disc diffusion, Etest and agar dilution for susceptibility testing of colistin against Enterobacteriaceae. Lett Appl Microbiol. 2011 Nov; 53(5): 546-51.

Mathews, A.A.; Thomas, M.; Appalaraju, B. and Jayalakshmi, J. (2010): Evaluation and comparison of tests to detect methicillin resistant $S$. aureus. Indian J Pathol Microbiol 2010; 53: 79-82.

McClure, J-A.; Conly, JM.; Lau, V.; Elsayed, S.; Louie, T.; Hutchins, W. and Zhang, K. (2006): Novel multiplex PCR assay for detection of the staphylococcal virulence marker PantonValentine leukocidin genes and simultaneous discrimination of methicillin-susceptible from -resistant staphylococci. J Clin Microbiol 44: 1141-114.

Mehrotra, M.; WANG, G. and Johnson, W.M. (2000): Multiplex PCR for Detection of Genes for Staphylococcus aureus Enterotoxins, Exfoliative Toxins, Toxic Shock Syndrome Toxin 1, and Methicillin Resistance. Journal of Clinical Microbiology. Vol. 38, No. 3.

Mona, A.A. Abdel Rahman; Jakeen, Are. El-Jakee and Soad, A. Nasef, ( 2014): Prevalance of salmonellae from layers and layer breeders farms, $2^{\text {nd }}$ Conference of Scientific Association of Animal Health Research Institute, 2-6/2/2014.PP 420: -432.ISSN: 2356-7767.

Motayo, B.; Akinduti, P.; Adeyakinu, F.; Okerentugba, P.; Nwanze, J.; Onoh, C.; Innocent-Adiele, H. and Okonko, I. (2013): Antibiogram and plasmid profiling of carbapenemase and extended spectrum Betalactamase (ESBL) producing Escherichia coli and Klebsiella pneumoniae in Abeokuta, South western, Nigeria. Afr Health Sci. 2013 Dec;13(4):1091-7. doi: 10.4314/ahs.v13i4.33.

Muhammad Ali Akond; Saidul Alam, S.M.R. Hassan, and Momena Shirin, (2009): Antibiotic Resistance of Escherichia Coli Isolated From Poultry and Poultry Environment of 
Bangladesh. Internet Journal of Food Safety, Vol.11, 2009, p. 19-23.

Murray, P.R.; Rosenthal, K.S.; Kobayashi, G.S. and Pfaller, M.A. (2002): Medical Microbiology, 4th edition, Mosby.

Nam, HM.; Lee, AL.; Jung, SC.; Kim, MN.; Jang, GC.; Wee, SH. and Lim, SK. (2011): Antimicrobial susceptibility of Staphylococcus aureus and characterization of methicillin-resistant Staphylococcus aureus isolated from bovine mastitis in Korea. Foodborne Pathog Dis. 2011 Feb; 8(2):231-8. doi: 10.1089/fpd.2010.0661. Epub 2010 Oct 30.

Obi, C.N. and Igbokwe, A.J. (2009): Microbiological Analyses of Freshly Laid and Stored Domestic Poultry Eggs in Selected Poultry Farms in Umuahia, Abia State, Nigeria,Research Journal of Biological Sciences. Year: 2009| Volume: 4 | Issue: 12 | Page No.: 12971303.ISSN:1815-8846

Otalu, OJ.; Kabir, J.; Okolocha, EC. and Umoh, VJ. (2011): Multi-drug Resistant Coagulase Positive Staphylococcus aureus from Live and Slaughtered Chickens in Zaria, Nigeria. International Journal of Poultry Science 10 (11): 871-875.

Oteo, J1.; Navarro, C.; Cercenado, E.; DelgadoIribarren, A.; Wilhelmi, I.; Orden, B.; García, C.; Miguelañez, S.; Pérez-Vázquez, M.; García-Cobos, S.; Aracil, B.; Bautista, V. and Campos, J. (2006): Spread of Escherichia coli strains with high-level cefotaxime and ceftazidime resistance between the community, long-term care facilities, and hospital institutions. J Clin Microbiol. 2006 Jul;44(7): 2359-66.

Otto, B.R.; Van Dooren, S.J.; Nuijens, J.H.; Luirink, J. and Oudega, B. (1998): Characterization of a hemoglobin protease secreted by the pathogenic Escherichia coli strain EB1. The Journal of Experimental Medicine, 188, 1091-1103.

Pérez-Pérez, A.; Peregrino-Bejarano, L.; CamachoVelázquez, M. and Miranda-Novales, MG. (2014): [Antimicrobial resistance in uropathogens isolated in a pediatric hospital]. Rev Med Inst Mex Seguro Soc. 2014;52 Suppl 2:S44-9.

Provence, D.L. and Curtiss, III, R. (1994): Isolation and cha racterization of a gene involved in hemagglutination by an avian pathogenic Escherichia coli strain. Infection and Immunity, 62, 1369-1380.

Pyzik, E.; Marek, A. and Hauschild, T. (2014): Characterisation of Staphylococcus aureus and Staphylococcus aureus - like strains isolated from table eggs. Bulletin of the Veterinary Institute in Pulawy. Volume 58, Issue 1, Pages $57-63$.
Randall, L.P.; Cooles, S.W.; Osborn, M.K.; Piddock, L.J.V. and Woodward, M.J. (2004): Antibiotic resistance genes, integrons and multiple antibiotic resistance in thirty-five serotypes of Salmonella enterica isolated from humans and animals in the UK. Journal of Antimicrobial Chemotherapy. 53, 208-216.

Rocha, A.C.G.B.; Rocha, S.L.S.; Lima-Rosa, C.A.V.; Souza, G.F.; Moraes, H.L.S.; Salle, F.O.; Moraes, L.B.; Salle, C.T.P. (2008): Genes associated with pathogenicity of avian Escherichia coli (APEC) isolated from respiratory cases of poultry. Pesq. Vet. Bras. vol.28 no.3 Rio de Janeiro Mar. 2008.

Rosario, C.C.; López, A.C.; Téllez, I.G.; Navarro, O.A.; Anderson, R.C. and Eslava, C.C. (2004): Serotyping and virulence genes detection in Escherichia coli isolated from fertile and infertile eggs, dead-in-shell embryos, and chickens with yolk sac infection. Avian Dis. 2004 Dec; 48(4): 791-802.

Saitanu, K.; Koowatananukul, C.; Jerngklinchan, J. and Sasipreeyajan, J. (1994): Detection of salmonellae in hen eggs in Thailand. Southeast Asian J Trop Med Public Health. 1994 Jun; 25(2): 324-7.

Sawai, T.; Tomono, K.; Yanagihara, K.; Yamamato, Y.; Kaku, M.; Hirakata, Y.; Koga, H.; Tashiro, T. and Kohno, S. (1997): Role of coagulase in a murine model of hematogenous pulmonary infection induced by intravenous injection of Staphylococcus aureus enmeshed in agar beads. Infect. immun. 65: 466-471.

Schmitz, F.; Krey, A.; Sadurski, R.; Verhoef, J.; Milatovic, D. and Fluit, A.D.C. (2001): Resistance to tetracycline and distribution of tetracycline resistance genes in European Staphylococcus aureus isolates. J. Antimicrob Chemother. 2001; 47: 239-240.

Sheikh, AA1.; Checkley, S.; Avery, B.; Chalmers, G.; Bohaychuk, V.; Boerlin, P.; Reid-Smith, R. and Aslam, M. (2012): Antimicrobial resistance and resistance genes in Escherichia coli isolated from retail meat purchased in Alberta, Canada. Foodborne Pathog Dis. 2012 Jul;9(7):625-31. doi: 10.1089/fpd.2011.1078. Epub 2012 Jun 25.

Stepień-Pyśniak, D.; Marek, A. and Rzedzicki, J. (2009): Occurrence of bacteria of the genus Staphylococcus in table eggs descended from different sources. Pol J Vet Sci. 2009; 12(4):481-4.

SuleimanA, Zaria LT.; Grema, HA. and Ahmadu, P. (2013): Antimicrobial resistant coagulase positive Staphylococcus aureus from chickens in Maiduguri, Nigeria. Sokoto Journal of Veterinary Sciences (2013). 11(1): 51-55. http://dx.doi.org/10.4314/sokjvs.v11i1.8. 
Swayne, D. E. (2013): Colibacillosis in Diseases of Poultry, Thirteenth Edition, ch18; 751-806.

Turtura, GC.; Massa, S. and Chazvinizadeh, $H$. (1990): Antibiotic resistance among coliform bacteria isolated from carcasses of commercially slaughtered chickens. Int. J. of Food Microbiol.11: 351-4.

Wada, M.; Lkhagvadorj, E.; Bian, L.; Wang, C.; Chiba, Y.; Nagata, S.; Shimizu, T.; Yamashiro, Y.; Asahara, T. and Nomoto, K. (2010): Quantitative reverse transcription-PCR assay for the rapid detection of methicillin-resistant Staphylococcus aureus. Journal of Applied Microbiology 108 (2010) 779-788.

Wani, S.A.; Samanta, I.; Bhat, M.A. and Nishikawa, $Y$. (2004): Investigation of shiga toxinproducing Escherichia coli in avian species in India. Letters in Applied Microbiology 2004, 39, 389-394.

Wen-jie, J.; Zhi-ming, Z.; Yong-zhi, Z.; Ai-jian, Q.; Hong-xia, S.; Yue-long, L.; Jiao, W. and Qianqian, W. (2008): Distribution of VirulenceAssociated Genes of Avian Pathogenic Escherichia coli Isolates in China. Agricultural Sciences in China, 7(12): 1511-1515.
Wooldridge, M. (2012): Evidence for the circulation of antimicrobial resistant strains and genes in nature and especially between humans and animals, Rev. sci. tech. Off. int. Epiz., 2012, 31 (1), 231-247.

Yaguchi, K.; Ogitani, T.; Osawa, R.; Kawano, M.; Kokumai, N.; Kaneshige, T.; Noro, T.; Masubuchi, K. and Shimizu, Y. (2007): Virulence Factors of Avian Pathogenic Escherichia coli Strains Isolated from Chickens with Colisepticemia in Japan. Avian Dis. 2007 Sep;51(3): 656-62.

Zahraei Salehi, T.; Safarchi, A.; Peighambari, S.M.; Mahzounieh, M. and Rabbani Khorasgani, $M$. (2007): Detection of stx1, stx2, eae, espB and hly genes in avian pathogenic Escherichia coli by multiplex polymerase chain reaction. J. Vet. Research. 62(2), 37-42.

Rosa Capita; Carlos Alonso-Calleja; Benito Moreno and María del Camino García-Fernández, (2001): Assessment of Baird-Parker Agar as Screening Test for Determination of Staphylococcus aureus in Poultry Meat. The Journal of Microbiology, December 2001, p.321-325.

\title{
تواجد المسببات المرضية البكتيرية المقاومة للمضادات الحيوية في بيض دجاج التربية المنزلية سماح عيا عبد السلام ، سعاد عب العزيز ناصف ، أحمد محد عبد الرحمن عرفان \\ Email: samaheid@ymail.com
}

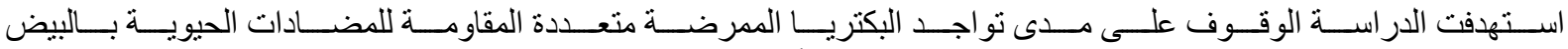

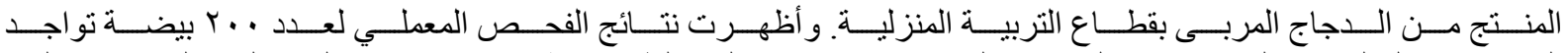

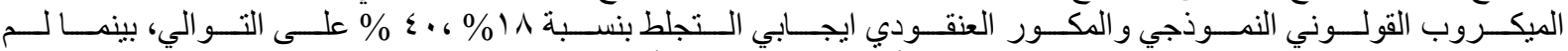

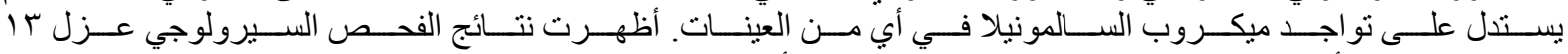

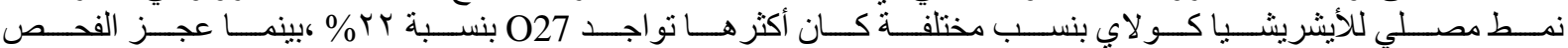

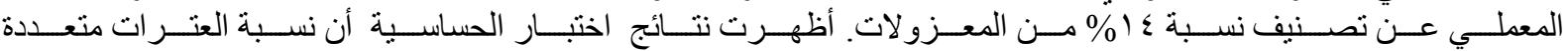

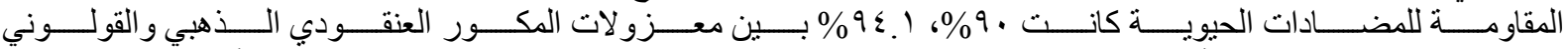

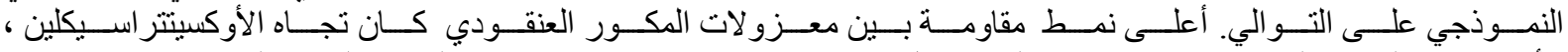

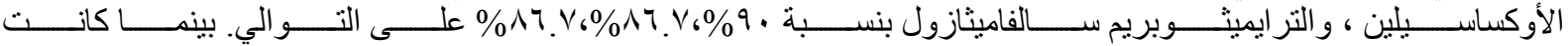

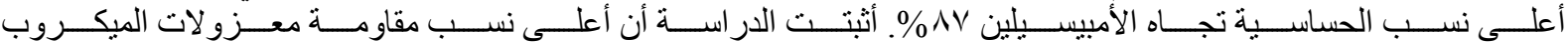

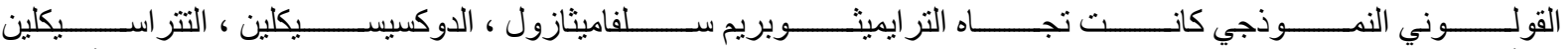

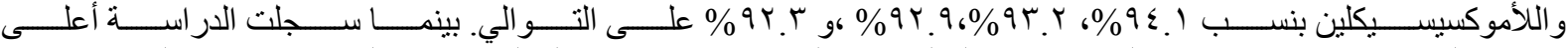

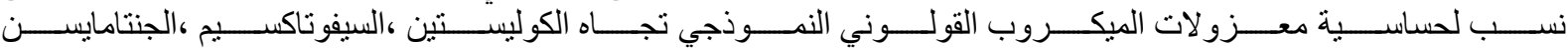

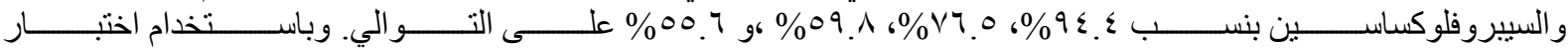

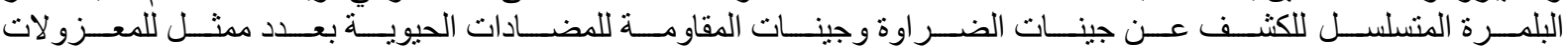

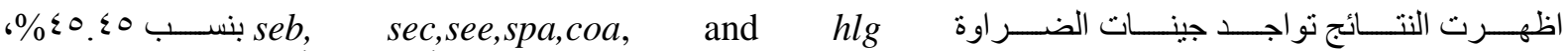

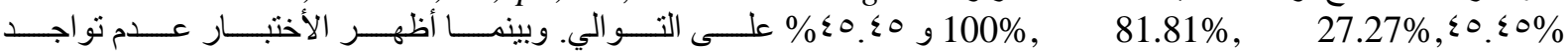

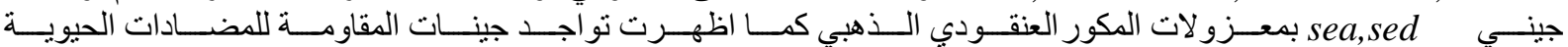
tetk blaz,mecA,

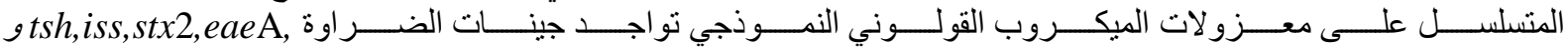
papC

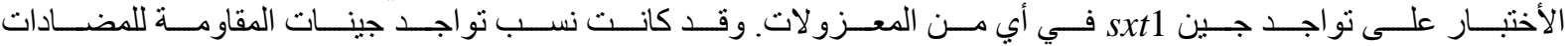

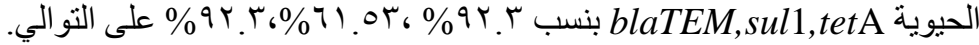

